\title{
Mitochondrial dysfunction and consequences in calpain-3-deficient muscle
}

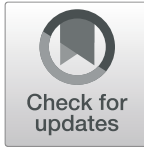

Vanessa E. Jahnke1, Jennifer M. Peterson², Jack H. Van Der Meulen', Jessica Boehler ${ }^{1}$, Kitipong Uaesoontrachoon ${ }^{1}$, Helen K. Johnston ${ }^{1,3}$, Aurelia Defour ${ }^{1}$, Aditi Phadke', Qing Yu', Jyoti K. Jaiswal ${ }^{1,3}$ and Kanneboyina Nagaraju ${ }^{1,3,4^{*}}$ (D)

\begin{abstract}
Background: Nonsense or loss-of-function mutations in the non-lysosomal cysteine protease calpain-3 result in limb-girdle muscular dystrophy type 2A (LGMD2A). While calpain-3 is implicated in muscle cell differentiation, sarcomere formation, and muscle cytoskeletal remodeling, the physiological basis for LGMD2A has remained elusive.
\end{abstract}

Methods: Cell growth, gene expression profiling, and mitochondrial content and function were analyzed using muscle and muscle cell cultures established from healthy and calpain-3-deficient mice. Calpain-3-deficient mice were also treated with PPAR-delta agonist (GW501516) to assess mitochondrial function and membrane repair. The unpaired $t$ test was used to assess the significance of the differences observed between the two groups or treatments. ANOVAs were used to assess significance over time.

Results: We find that calpain-3 deficiency causes mitochondrial dysfunction in the muscles and myoblasts. Calpain3-deficient myoblasts showed increased proliferation, and their gene expression profile showed aberrant mitochondrial biogenesis. Myotube gene expression analysis further revealed altered lipid metabolism in calpain-3deficient muscle. Mitochondrial defects were validated in vitro and in vivo. We used GW501516 to improve mitochondrial biogenesis in vivo in 7-month-old calpain-3-deficient mice. This treatment improved satellite cell activity as indicated by increased MyoD and Pax7 mRNA expression. It also decreased muscle fatigability and reduced serum creatine kinase levels. The decreased mitochondrial function also impaired sarcolemmal repair in the calpain-3-deficient skeletal muscle. Improving mitochondrial activity by acute pyruvate treatment improved sarcolemmal repair.

Conclusion: Our results provide evidence that calpain-3 deficiency in the skeletal muscle is associated with poor mitochondrial biogenesis and function resulting in poor sarcolemmal repair. Addressing this deficit by drugs that improve mitochondrial activity offers new therapeutic avenues for LGMD2A.

Keywords: LGMD2A, Mitochondria, Calpain-3 deficiency, Muscle membrane repair

\footnotetext{
* Correspondence: nagaraju@binghamton.edu

'Center for Genetic Medicine Research, Children's National Research Institute,

Children's National Hospital, Washington, D.C., USA

${ }^{3}$ Department of Genomics and Precision Medicine, George Washington

University School of Medicine and Health Sciences, Washington, D.C., USA

Full list of author information is available at the end of the article
}

(c) The Author(s). 2020 Open Access This article is licensed under a Creative Commons Attribution 4.0 International License, which permits use, sharing, adaptation, distribution and reproduction in any medium or format, as long as you give appropriate credit to the original author(s) and the source, provide a link to the Creative Commons licence, and indicate if changes were made. The images or other third party material in this article are included in the article's Creative Commons. licence, unless indicated otherwise in a credit line to the material. If material is not included in the article's Creative Commons licence and your intended use is not permitted by statutory regulation or exceeds the permitted use, you will need to obtain permission directly from the copyright holder. To view a copy of this licence, visit http://creativecommons.org/licenses/by/4.0/. The Creative Commons Public Domain Dedication waiver (http://creativecommons.org/publicdomain/zero/1.0/) applies to the data made available in this article, unless otherwise stated in a credit line to the data. 


\section{Background}

Calpains are non-lysosomal, $\mathrm{Ca}^{2+}$-dependent, cysteine proteases [1]. In addition to the two ubiquitous calpain isoforms CAPN1 and CAPN2, the skeletal muscles also express CAPN3 protein also known as p93 or calpain-3 [2]. Although this $94-\mathrm{kDa} \mathrm{Ca}{ }^{2+}$-dependent cysteine protease is known to localize to sarcomeres through binding the giant sarcomeric protein titin (also referred to as connectin) [3], its physiological functions are yet to be fully elucidated. CAPN3 has been implicated in muscle repair and maintenance [4], myogenesis [5], NF- $\mathrm{kB}$ signaling, and apoptosis [6, 7]. Loss-of-function mutations in the CAPN3 gene lead to the autosomal recessive form of limb-girdle muscular dystrophy (LGMD) type 2A (LGMD2A).

LGMD2A is one of the most frequent subtypes of autosomal recessive muscular dystrophy, accounting for up to $30 \%$ of all recessive LGMD cases [8]. Disease onset usually occurs in the second decade of life but can vary from age 2.5 to 50 years [9-11]. Progression of the disease is slow, leading to loss of ambulation during adulthood and a near-normal life expectancy [12]. Histopathological features of the muscle include necrosis, regeneration, and variation in muscle fiber diameter [13-15]. More than 440 different pathogenic mutations of the CAPN3 gene have been reported in LGMD2A patients [4]. These mutations are distributed along the entire length of the gene product and include missense, nonsense, frame-shift, and deletion mutations [15-18].

Three independent mouse models have been used to study the biology of CAPN3 and its role in diseases [6, $19,20]$. Findings from all three mouse models highlight the importance of CAPN3 in skeletal muscle biology, but the precise mechanism by which CAPN3 mutations lead to the LGMD2A phenotype has remained unclear. Electron microscopic examination of LGMD2A patient biopsies has implicated mitochondrial abnormalities in the skeletal muscle, providing insights into one possible mechanism in the disease process [21]. Mitochondria play important roles in regulating muscle repair and muscle mass maintenance [22-29]. The physiological importance of mitochondrial activity has for many decades been associated with ATP synthesis and the maintenance of an energetic steady state in the cell. However, numerous studies have demonstrated that mitochondria are not only a locus of energy synthesis but also an essential component of the regulation of numerous physiological mechanisms including apoptosis [30], aging [31], and myogenesis [32]. As far back as the early 1950s, Warburg demonstrated a link between respiration and proliferation such that cells preparing to proliferate shift to glycolytic metabolism [33]. Multiple studies have demonstrated the involvement of mitochondria in muscle proliferation and differentiation [22-29]. More recently, we have identified that mitochondrial activity is also required for the acute repair of injured muscle fibers through a process that does not depend on mitochondrial ATP production, but instead mitochondrial activity-dependent redox signaling [34, 35]. Further, we have found defects in this specific mitochondrial activity contribute to the poor repair of injured muscle fibers in Duchenne muscular dystrophy [36], myositis [37], and muscular dystrophy due to the lack of MIUC1 [38]. With such a variety of roles, mitochondria are central regulators of the mechanisms involved in muscle growth, repair, and maintenance of mass. In this study, we have demonstrated that CAPN3 deficiency in the skeletal muscle is characterized by mitochondrial dysfunction, which impacts both myoblasts and myofibers. This dysfunction compromises muscle fiber repair, but drugs that promote mitochondrial biogenesis improve myofiber repair in Capn3-deficient mice and offer potential new therapies for LGMD2A.

\section{Materials and methods}

Animal experiments

All mice were handled according to our Institutional Animal Care and Use Committee guidelines under approved protocols. Capn3-deficient mice were kindly provided by Dr. Melissa Spencer (the University of California, Los Angeles). Capn3-deficient mice were provided on a C57BL/6 background and bred homozygous. Therefore, C57BL/6J mice (The Jackson Laboratory, Bar Harbor, ME) were selected as appropriate controls. All mice were age-matched for experiments. Mice were housed in an individually vented cage system on a 12-h light-dark cycle, with standard mouse chow and water provided ad libitum. Capn3-deficient were bred and genotyped according to the method previously described (Fig. 1a) [19]. The 9-month time point chosen for the drug study was based on systematic phenotyping performed in our laboratory on Capn3-deficient mice.

\section{Generation of immortalized Capn3-deficient cells}

Capn3-deficient mice were bred with $H-2 K^{b}$-ts $A 58$ immortomice ( $\mathrm{Tg}(\mathrm{H} 2-\mathrm{K} 1$-tsA58)6Kio/LicrmJ, The Jackson laboratory). The F1 generation heterozygotes for SV40 large T antigen and the Capn3-mutated gene were bred together to produce homozygous mice with the Capn3-mutated gene. The following primer pairs were used for genotyping (LTR2: AAA TGG CGT TAC TTA AGC TAG CTT GC; C3upA: GAA AGG GAC AGG AGA AAT GGA G; C3dnB: CCT GAA ACT TCA AGC CTC TGT TC) and SV40 large $T$ carrier (forward primer: T ant-R 5' GAG TTT CAT CCT GAT AAA GGA GG; reverse primer: T ant-F 5' GTG GTG TAA ATA GCA AAG CAA GC). Three-week-old mice were euthanized, shaved, and placed in iodide water $(1 / 20 \mathrm{v} / \mathrm{v})$ for 


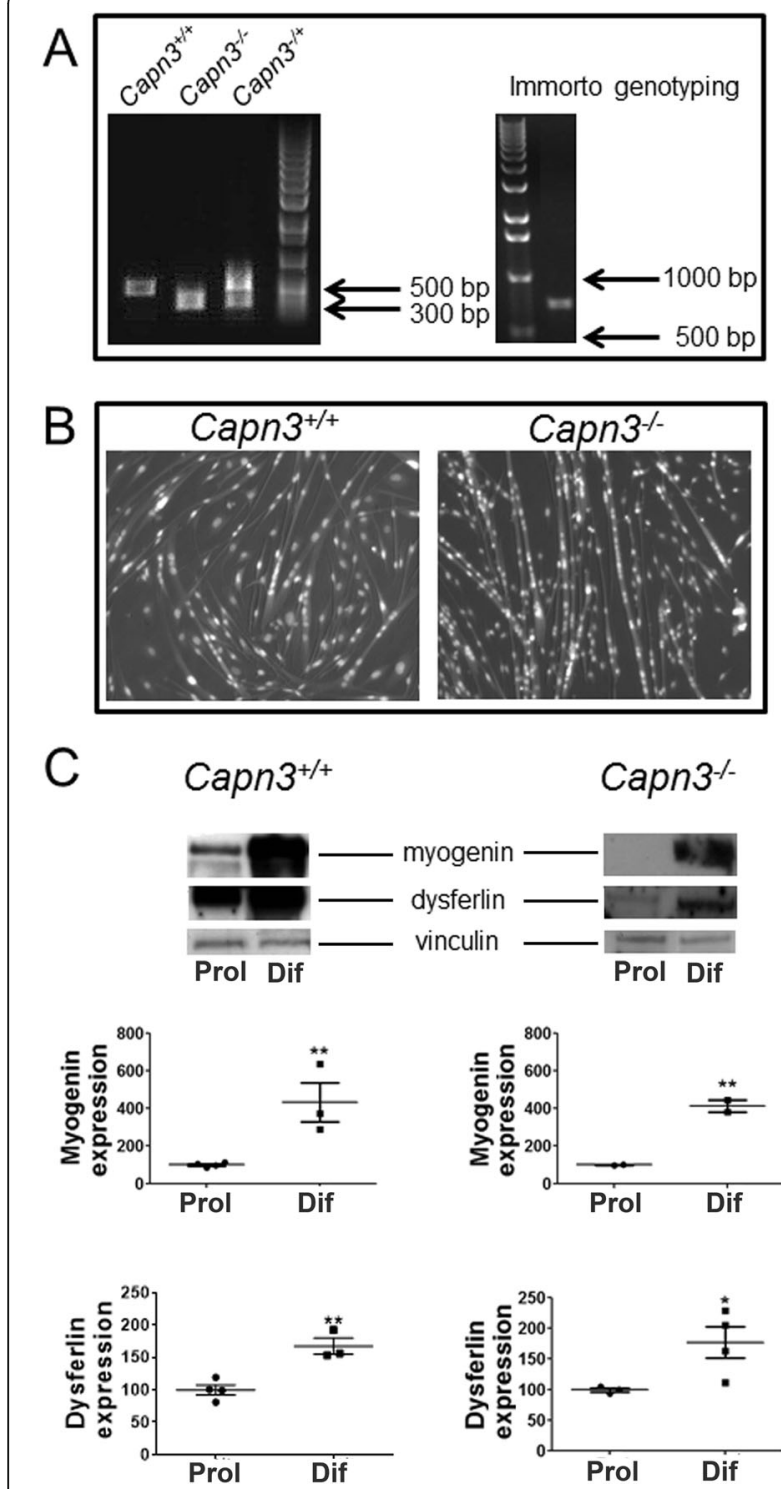

Fig. 1 Capn3-deficient and Capn3-sufficient immortalized primary muscle cells. Genotyping: agarose gel showing the WT $\left(\mathrm{Capn}^{+/+}\right)$ Capn3 gene band at $500 \mathrm{bp}$ and the Capn3-deficient (Capn3 ${ }^{-1-}$ ) gene band at $300 \mathrm{bp}$. The large T gene is shown at $700 \mathrm{bp}(\mathbf{a})$. Differentiation test performed on $\mathrm{Capn}^{+/+}$and $\mathrm{Capn}^{-/-}$primary immortalized cell cultures. Hoechst 33342 was used to stain the nuclei and show multinucleated myotubes formation after 2 days in a low-serum medium (b). Western blots and quantification of muscle-specific proteins in myoblasts and myotubes. Myogenin and dysferlin were used to verify the myogenicity of cells. The expression of myogenin and dysferlin was normalized to vinculin loading control. Since myogenin and dysferlin expression varied between calpain-deficient and calpain-sufficient myoblasts, we have expressed increased expression of these differentiation markers in myotubes as a percentage of expression seen in myoblasts (c). Analyses were performed on $n=4$ different cell culture flasks for proliferation and $n=3$ for differentiation. ${ }^{*}$ Significantly different with $p<0.01$; ${ }^{*}$ significantly different with $p<0.05$
$5 \mathrm{~min}$, and their extensor digitorum longus (EDL) muscles were harvested from tendon to tendon and incubated in a solution of DMEM + fresh collagenase $(2 \mathrm{mg} /$ $\mathrm{ml}$ ) at $35^{\circ} \mathrm{C}$ under agitation for $2 \mathrm{~h}$. After the collagenase digestion, the muscle fibers were isolated with Pasteur pipettes and rinsed in four successive baths of DMEM + $5 \%$ penicillin/streptomycin (P/S). Single fibers were plated at $33^{\circ} \mathrm{C}$ in 24-well plates coated with Matrigel (in $\mathrm{H} 2 \mathrm{~K}$ proliferation medium [H2KPM]: $20 \%$ heatinactivated FBS, $4 \mathrm{mM}$ L-glutamine, $2 \% \mathrm{v} / \mathrm{v}$ chick embryo extract, and $1 \%$ penicillin/streptomycin $[100 \mathrm{U} / \mathrm{ml}$ to $100 \mu \mathrm{g} / \mathrm{ml}]$ in DMEM and supplemented with fresh gamma-interferon at $20 \mathrm{U} / \mathrm{ml})$. Satellite cell migration was followed during the next $8 \mathrm{~h}$. Fibers were removed as soon as a few myoblasts or clones were visible. The clones were allowed to proliferate to $70 \%$ confluence and harvested, and then the trypsinized cells were placed in a series of culture dishes of varying sizes. The cells were then harvested; one portion was allowed to differentiate, and the cells were then frozen (in H2KPM + $10 \%$ DMSO) and stored at $-80^{\circ} \mathrm{C}$.

\section{Immortalized muscle cell cultures}

Conditionally immortalized control C57BL/6 and Capn3-deficient myoblast clones contain a temperaturesensitive immortalizing gene, the tsA58 mutation of the SV40 large $\mathrm{T}$ antigen, under the control of the $\mathrm{H}-2 \mathrm{~K}^{\mathrm{b}}$ inducible promoter [39]. When induced with interferongamma (IFN- $\gamma$ ), the tsA58 protein is expressed, allowing the cells to proliferate at $33{ }^{\circ} \mathrm{C}$. Myoblasts were plated and maintained on gelatin-coated dishes $(0.01 \%$ gelatin $)$ in $\mathrm{H} 2 \mathrm{KPM}$ at $33^{\circ} \mathrm{C}$ and $10 \% \mathrm{CO}_{2}$ in a humidified incubator. Cultures were fed every 2-3 days with H2KPM, and fresh IFN- $\gamma(20 \mathrm{U} / \mathrm{ml})$ was added to the culture medium at each feeding. Cells were grown to near confluence, harvested with trypsin/EDTA $(0.5 / 0.2 \mathrm{~g} / \mathrm{l})$, and centrifuged at $800 \mathrm{~g}$ for $3 \mathrm{~min}$. The cell pellet was used for DNA, RNA, or protein extraction or resuspended in $\mathrm{H} 2 \mathrm{KPM}$. Under these conditions, the cells doubled every $24-30 \mathrm{~h}$ at $33{ }^{\circ} \mathrm{C}$ and fused with $>50 \%$ efficiency into multinucleated sarcomeric tropomyosin-positive muscle fibers when switched to $37^{\circ} \mathrm{C}$ in the absence of IFN- $\gamma$.

\section{Gene expression profiling using Illumina BeadChip microarrays}

Total RNA was extracted from the tibialis anterior (TA) muscle using TRIzol Reagent and an RNeasy mini kit (Qiagen, Valencia, CA) from the sections of frozen pellets of proliferating cells or cells that had been allowed to differentiate for 5 days. RNA was stored at $-80^{\circ} \mathrm{C}$ until used. The quality of the RNA from each sample was assessed using an Agilent RNA 6000 Nano kit in an Agilent 2100 Bioanalyzer (Agilent Technology, Palo Alto, CA). Biotinylated cRNA was prepared from $250 \mathrm{ng}$ 
of total RNA using an Illumina Totalprep RNA amplification kit (Ambion, Inc., Austin, TX) according to the manufacturer's protocol. Hybridization of the samples to a MouseWG-6 v2.0 Expression BeadChip (Illumina, Inc., San Diego, CA), washing, labeling with Cy3-streptavidin, and scanning of the BeadChip were performed according to the manufacturer's protocol. The Illumina data were extracted using Genome Studio (software provided by Illumina), with no background subtraction, then normalized using the "quantiles" function. The data generated from the Genome Studio were then exported to the Partek Genomics Suite software for further analysis. In Partek, the genes differentially expressed between Capn3deficient and Capn3-sufficient cells were filtered by a $p$ value with a false discovery rate of $\leq 0.05$ and a fold change of $\geq 4$. The significant networks (identified by using the "Core Analysis" function) associated with the differentially expressed genes for each of the comparisons were analyzed using the Ingenuity Pathway Analysis program (Ingenuity System Inc., CA).

\section{Assessment of mitochondrial function using flow cytometry analyses}

Mitochondrial content, inner membrane potential $(\Delta \Psi)$, ROS production, and intracellular calcium were assessed with 10-nonyl acridine orange (NAO, Sigma-Aldrich, St. Louis, MO), 3,3'-dihexyloxacarbocyanine iodide (DiOC6, Invitrogen), 2',7'-dichlorodihydrofluorescein diacetate (H2DFCDA, Invitrogen), and Fluo4-AM (Invitrogen), respectively, as described [25]. Cells were analyzed on a FACSCalibur (BD Biosciences, San Jose, CA) with BD Cell Quest ProTM 4.0.2.

\section{Analysis of mitochondrial DNA-to-nuclear DNA ratios}

Total DNA was extracted from muscle cells using a DNeasy blood and tissue kit (Qiagen). The mitochondrial DNA (mtDNA) ratio was calculated using real-time quantitative PCR by measuring the threshold cycle ratio $(\Delta \mathrm{Ct})$ of a mitochondrial-coded gene (ND1, forward 5'-GGA CCT AAG CCC AAT AAC GA-3', reverse 5'-GCT TCA TTG GCT ACA CCT TG-3') relative to nuclear DNA (nDNA) using a nuclear-coded gene (beta-globulin, forward 5'-CTT CTG GCT ATG TTT CCC TT-3', reverse 5'-GTT CTC AGG ATC CAC ATG CA-3').

\section{Western blotting and LDH activity}

Protein homogenates were extracted from the tibialis anterior (TA) muscle as previously described using RIPA buffer (Invitrogen) [40]. Proteins were separated on $4-12 \%$ Nupage Bis/Tris gels. After electrotransfer, the membranes were saturated with $5 \%$ non-fat dry milk $\left(1 \mathrm{~h}, 20^{\circ} \mathrm{C}\right)$ and incubated overnight with primary antibody against transcription factor A, mitochondrial (TFAM; 1:500, Cell Signaling), pyruvate dehydrogenase kinase (PDK1) (1:5000, Santa
Cruz), dysferlin (1:500, Dako), myogenin (1:1:500, Dako), or vinculin $(1: 10,000$, Sigma), then with the corresponding secondary antibodies (1:3000-1:5000) for $90 \mathrm{~min}$. Immunoreactivity was determined by chemiluminescence and quantified with Quantity One (Bio-Rad).

Lactate dehydrogenase (LDH) activity of muscle lysates was measured using $2.5 \mu \mathrm{l}$ of protein extract (1:2 dilution) and $225 \mu \mathrm{l}$ assay buffer $(2.5 \mathrm{ml}$ of $1 \mathrm{M}$ Tris $[\mathrm{pH}$ 7.6], $500 \mu \mathrm{l}$ of $200 \mathrm{mM}$ EDTA, $500 \mu \mathrm{l}$ of $5 \mathrm{mM}$ NADH, and $48 \mathrm{ml}$ water). Oxidation of $\mathrm{NADH}, \mathrm{H}^{+}$was recorded after pyruvate addition $(10 \mu \mathrm{l}, 100 \mathrm{mM})$. NADH fluorescence was detected by a luminescence/fluorescence analyzer (Mithras LB 940, Berthold Technologies). LDH activity was normalized to the protein concentration.

\section{Assessment of cell proliferation using CFSE}

Immortalized H2K cells (described above) were cultured in H2KPM, trypsinized, and stained with carboxyfluorescein diacetate succinimidyl ester (CFSE) dye $(10 \mu \mathrm{M}, 10$ $\min$ at $37^{\circ} \mathrm{C}$ ). One million cells were stored in $4 \%$ formalin and kept at $4{ }^{\circ} \mathrm{C}$ until analysis. The left-over cells were cultured and harvested at several time points to perform the proliferation kinetics. Cytometry analyses were done to analyze the fluorescence lost during proliferation using the FlowJo software (FlowJo, LLC, OR, USA). We used CFSE fluorescent dye to assess proliferation. A decrease in fluorescence occurs as dyes are evenly diluted into daughter cells with subsequent cell divisions measured as distinct peaks during analysis. The "generation 0 " peak was set by drawing a gate around the unstimulated peak in the proliferation assay. The "generation 0 " peak represents the undivided cells and had a relatively consistent intensity and coefficient of variation (CV) across the samples collected in the proliferation assay. The fluorescence of CFSE was assessed in each harvested cell time point. The proliferation analysis was applied to each sample. The FlowJo software estimated the optimal peak ratio and CV to represent the population according to the characteristics of the "generation 0." Each peak represents a successive generation of cell division. The proliferation index was automatically calculated by the software according to the fluorescence analyses. The proliferation index represents the total number of divisions by the number of cells that have undergone division. This gives a more comprehensive understanding of how fast cells are growing indicating the number of divisions completed on average per cell that is proliferating and can reflect the kinetics of behavior of different cell genotypes (Capn3-deficient and Capn3sufficient) under the same conditions.

\section{Treatment of Capn3-deficient mice with the PPAR-delta agonist, GW501516}

At 8 months of age, the mice were given GW501516 $(7.5 \mathrm{mg} / \mathrm{kg} \quad[80 \mu \mathrm{l}] ; \quad$ Alexis Biochemicals/Enzo Life 
Sciences) by intraperitoneal injection 5 days/week for 4 weeks. DMSO $(1 / 2 \mathrm{v} / \mathrm{v}$ in PBS) was used as a vehicle control. The concentration of DMSO was the same in the drug solution and the vehicle control. Rotarod activity assessments were performed pre- and post-treatment.

\section{Assessment of motor coordination using Rotarod apparatus}

Mice were trained on the Rotarod (Ugo Basile, VA, Italy) for 2 days before data were collected. Each acclimatization session consisted of four training sessions, 2 per day, and each session lasted $120 \mathrm{~s}$ at a speed of $5 \mathrm{rpm}$. Each trial consisted of placing the mouse on the rod at $10 \mathrm{rpm}$ for $60 \mathrm{~s}$ (the stabilizing period) followed by acceleration from 10 to $40 \mathrm{rpm}$ within the first $25 \mathrm{~s}$ until the animal fell from the rod or until $180 \mathrm{~s}$ was reached. If the animals fell during the stabilizing period, they were placed back on the rod to complete the session. The total testing time was $240 \mathrm{~s}$ (a 60-s stabilization time and 180-s test time). Each trial was performed twice a day (with a 2-h interval between sessions) for 3 consecutive days. The latency to fall (in seconds) was recorded, and all six scores per mouse were averaged and were recorded as latency to fall (in seconds) for each mouse.

\section{Behavioral activity measurement}

The open-field activity was measured using an openfield digiscan apparatus (Omnitech Electronics, Columbus, $\mathrm{OH}$ ) before and after drug treatment. All mice were acclimatized for 4 days before the actual data collection. The data were collected every $10 \mathrm{~min}$ over a 1 -h period each day for 4 days. The horizontal distance, total distance, movement number, and movement number were used to assess overall behavioral activity.

\section{Serum collection and preparation of muscle lysates}

Blood was collected by heart puncture immediately after euthanasia and placed into Eppendorf tubes packed on ice. The blood samples were centrifuged at $4{ }^{\circ} \mathrm{C}$ for 10 min at $10,000 \mathrm{~g}$. The serum was then collected, placed in a new Eppendorf tube, and frozen at $-80^{\circ} \mathrm{C}$ until used.

Whole frozen muscles were placed in individual Eppendorf tubes packed on ice with $200 \mu \mathrm{l}$ of RIPA buffer supplemented with proteinase inhibitor cocktail. The muscles were quickly cut into small pieces with sharp scissors and homogenized with a motorized pestle for 1 min, then centrifuged at $10,000 \mathrm{~g}$ for $10 \mathrm{~min}$ at $4{ }^{\circ} \mathrm{C}$. The supernatant was collected and stored at $-80^{\circ} \mathrm{C}$. Before storage, the protein concentration was measured using the Bio-Rad modified-Lowry method.

\section{RNA extraction from muscle tissue for gene expression profiling}

RNA was extracted using a miRNeasy Mini Kit (Qiagen). Reverse transcription (RT) was performed with a
TaqMan microRNA reverse transcription kit (Life Technologies Co., Applied Biosystems, Carlsbad, CA). mRNA expression was calculated using real-time quantitative PCR by measuring the threshold cycle ratios $(\Delta \mathrm{Ct})$ using the following primer pairs for PPAR $\delta$ mRNA (5'-CGC ATG AAG CTG GAG TAC GA-3', 5' -TGG CAC TTG TTG CGG TTC T-3'), MyoD mRNA (5'-TCC TCC AGC CTG TAC TGA CC-3', 5' -CCT TGG CTC AAC TTC TCT G-3'), Pax7 mRNA (5'-CTG TGT GGA CAG GCT CAC G-3', 5'-CAT CAA GCC AGG AGA CAGC-3'), and endogenous control GAPDH mRNA (5' CCG TTC AGC TCT GGG ATG AC-3', 5'-TTC TCA GCA ATG CAT CCT GC-3').

\section{Measurement of creatine kinase}

Creatine kinase (CK) determination was performed according to the manufacturer's instructions using a standard spectrophotometric method with an enzyme-coupled assay reagent from Fisher Scientific (CK10). Absorption at $340 \mathrm{~nm}$ was measured every minute for $2 \mathrm{~min}$ at $37^{\circ} \mathrm{C}$ to calculate the enzyme activity. Duplicate measurements were done on each serum sample, and the data were expressed as units per liter for serum samples or units per protein concentration for muscle lysates.

\section{Measurement of the contraction properties of the EDL and soleus muscles}

Mice were anesthetized with $100 \mathrm{mg} / \mathrm{kg}$ ketamine and $10 \mathrm{mg} / \mathrm{kg}$ xylazine. The EDL and soleus muscles were isolated and placed in Ringer's solution $(137 \mathrm{mM} \mathrm{NaCl}$, $24 \mathrm{mM} \mathrm{NaHCO}, 11 \mathrm{mM}$ glucose, $5 \mathrm{mM} \mathrm{KCl}, 2 \mathrm{mM}$ $\mathrm{CaCl}_{2}, 1 \mathrm{mM} \mathrm{MgSO}, 1 \mathrm{mM} \mathrm{NaH_{2 }} \mathrm{PO}_{4}$, and $0.025 \mathrm{mM}$ turbocurarine chloride) maintained at $25^{\circ} \mathrm{C}$ and bubbled with $95 \% \mathrm{O}_{2}-5 \% \mathrm{CO}_{2}$. Contractile properties were measured according to Brooks and Faulkner [41], using an in vitro test apparatus (model 305B, Aurora Scientific). A fatigue protocol was performed for both the EDL and soleus muscles: 5-min duration, one contraction every 4 s, 75 contractions in total. The stimulation duration for the EDL muscle was $300 \mathrm{~ms}$ and for the soleus muscle $1000 \mathrm{~ms}$. Both muscles were stimulated with a frequency of $100 \mathrm{~Hz}$. We have assessed specific force $\left(\mathrm{kN} / \mathrm{m}^{2}\right)$, twitch-to-tetanus ratio, half-relaxation time (HRT) (seconds), and time to peak tension twitch (TTP) (seconds) of the EDL muscle as well as maximal force relative to baseline for the EDL and soleus muscles was calculated.

\section{Measurement of membrane repair using laser injury}

Freshly isolated whole muscle (biceps brachii, soleus, or EDL) or isolated single fibers from the muscles of 3month-old male mice were used. The whole muscles were used fresh, while isolated fibers were placed on Matrigelcoated dishes in DMEM and allowed to attach for 1-2 days in an incubator at $37^{\circ} \mathrm{C}$ with $5 \% \mathrm{CO}_{2}$. For imaging 
response to laser injury, the intact muscles or isolated fibers were transferred to a cell imaging medium previously described [42], incubated with $1.5 \mu \mathrm{g} / \mathrm{ml}$ of $N$-(3-triethylammoniumpropyl)-4-(4-(dibutylamino)styryl)yridinium dibromide (FM ${ }^{\bullet} 1$-43) (Life Technologies, CA) in Tyrode's buffer and imaged on an inverted Olympus IX81 microscope (Olympus America, PA) custom-equipped with a pulsed laser, AblateTM (Intelligent Imaging Innovations, Inc. Denver, CO), and diode laser of $488 \mathrm{~nm}$ (Cobolt, Sweden). Images were acquired using Evolve 512 EMCCD (Photometrics, Tucson, AZ) at $1 \mathrm{~Hz}$. Image acquisition and laser injury were both controlled using Slidebook 5.0 (Intelligent Imaging Innovations, Inc., Denver, CO). To decrease mitochondrial activity in the wild-type (WT) muscles, carbonyl cyanide 3-chlorophenylhydrazone (CCCP; $2 \mu \mathrm{M})$ was added to the preparation before laser injury. To increase the mitochondrial activity in Capn3-deficient muscle, pyruvate $(100 \mathrm{mM})$ was added to the preparation $30 \mathrm{~min}$ before laser injury. DiOC6 dye $(1.5 \mu \mathrm{M})$ was used to control the increase in mitochondrial activity with pyruvate treatment; in this case, no $\mathrm{FM}^{\ominus} 1-43$ was used in the muscle because of the spectral overlap in the fluorescence emission of the two dyes.

\section{Statistical analyses}

The mean difference between WT and Capn3-deficient mice, muscle, or cells was determined by the unpaired $t$ test. Kinetics statistics were measured using 2-way ANOVA.

\section{Results}

\section{Characterization of Capn3-deficient and Capn3-sufficient} immortomouse muscle cells

Immortalized muscle cells were genotyped for Capn3 and SV40 large $\mathrm{T}$ antigen (Fig. 1a). A portion of the cloned cells was allowed to proliferate until $80-90 \%$ of confluence and differentiated for 2 days in a differentiation medium. After 2 days of differentiation, multinucleated fibers with twitching were observed in the cultures (Fig. 1b). Myogenin and dysferlin expression confirmed successful switching of the myoblasts from proliferation to differentiation stages of these cell cultures (Fig. 1c). Further, a comparison between the healthy and Capn3-deficient cells showed no difference in the expression levels of both these differentiation marker proteins.

\section{Gene expression analysis of Capn3-deficient and Capn3- sufficient muscle cells}

We performed BeadChip arrays to analyze the gene expression patterns in WT and Capn3-deficient myoblasts and myotubes. The dendrogram illustrates the hierarchical clustering of differentially expressed genes in WT and Capn3-deficient myoblasts (Fig. 2a) and myotubes
(Supplemental Fig. 1A). This identified 54 differentially expressed myoblast genes that were directly related to mitochondrial biogenesis, metabolism, lipid metabolism, and protein transport (Fig. 2a, b and Table 1). Comparison of the Capn3-deficient myotubes showed differential expression of genes in these same pathways (Supplemental Fig. 1A, B). A list of altered genes related to mitochondrial biogenesis, metabolism, lipid metabolism, and protein transport and their respective fold changes for myoblasts and myotubes is available in the supplemental excel file.

\section{Assessment of mitochondrial abundance and activity in Capn3-deficient myoblasts}

With the dysregulation observed in mitochondrial gene expression, we assessed mitochondrial content in myoblasts using the mtDNA/nDNA ratio as a measure for it. This showed that when compared to WT myoblasts, mitochondrial content was reduced by 2 -fold in the Capn3-deficient myoblasts (Fig. 3a). As another measure of mitochondrial content, we monitored the level of mitochondrial lipid-cardiolipin using the cardiolipin stain 10-nonyl acridine orange fluorescence (NAO). Flow cytometry analysis of NAO fluorescence in live, proliferating myoblasts showed significantly lower fluorescence in Capn3-deficient compared to WT cells (Fig. $3 \mathrm{~b})$. Together, these results indicate that there is a deficit in mitochondrial content in the Capn3-deficient muscle cells.

\section{Assessment of mitochondrial membrane potential in Capn3-deficient myoblasts}

Next, to assess mitochondrial activity, we monitored the mitochondrial membrane potential $(\Delta \Psi)$. For this, we measured DiOC6 fluorescence by fluorescent microscopy. WT myoblasts had stronger and denser fluorescent staining than Capn3-deficient myoblasts (Fig. 4a). This suggested that Capn3-deficient myoblasts have reduced mitochondrial respiration compared to WT cells. When quantitated, Capn3-deficient myoblasts had a 2fold reduced DiOC6 staining (Fig. 4b). The specificity of the DiOC6 staining for mitochondrial inner membrane potential was confirmed by the loss of DiOC6 fluorescence by the mitochondrial uncoupler (CCCP) (Fig. 4c). To assess if reduced DiOC6 labeling reflects reduced mitochondrial abundance or activity, we normalized DiOC6 fluorescence to NAO fluorescence. This normalized fluorescence was also significantly reduced in the Capn3-deficient myoblasts, demonstrating that these cells exhibit reduced mitochondrial potential indicative of reduced mitochondrial activity, even after adjusting to mitochondrial content (Fig. 4d). 


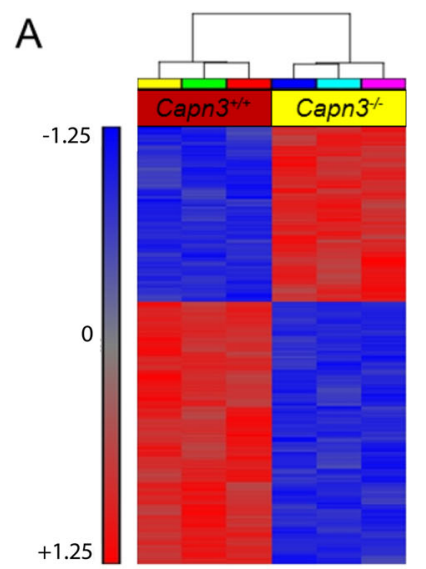

B

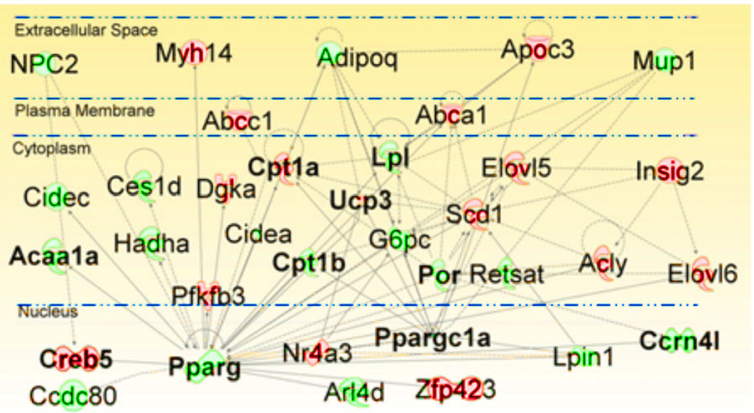

Fig. 2 Gene expression profiling of Capn3-deficient vs. Capn3-sufficient myoblasts with an Illumina BeadChip array. Dendrogram results attesting the good clustering of Capn3-deficient $\left(\mathrm{Capn}^{-/-}\right)$myoblast samples when compared to corresponding WT (Capn $3^{+/+}$) muscle cells using Partek Genomics Suite, a statistical analysis and interactive visualization software (a). Pathway analysis was done using the Ingenuity Pathways Analysis software that allows functional integration of molecular pathways. Ingenuity pathway analysis demonstrating changes in mitochondrial biogenesis, lipid metabolism, and protein transport in myoblasts. Pink indicates an upregulation and green indicates a downregulation of the specific gene in $\mathrm{Capn}^{-/-}$myoblasts compared to $\mathrm{Capn}^{+/+}$myoblasts (b). Three different samples were used per group. cRNA was synthesized from $250 \mathrm{ng}$ of total RNA for each sample. Gene pathways were prepared by ingenuity pathways analysis according to a gene list based on the interaction of a gene candidate with a $p$ value of 0.001 and a fold increase $\geq 4$

\section{Assessment of mitochondrial metabolism in Capn3- deficient mouse muscle}

To examine if the mitochondrial deficit we observed in cultured myoblasts truly represents in vivo mitochondrial deficit in Capn3-deficient muscle, we evaluated this deficit in the TA muscles. With the importance of the mitochondrial transcription factor TFAM in mitochondrial biogenesis, we measured the level of this protein and found it to be significantly reduced in Capn3-deficient TA muscle compared to WT (Fig. 5a, b). Similarly, using the mitochondrial matrix protein, PDK1, we also found reduced mitochondrial abundance in Capn3-deficient tibialis anterior (TA) muscle (Fig. 5a, c). Next, we examined the abundance of the enzyme-creatine kinase (CK) found in the cytoplasm and mitochondria, by measuring the activity of this enzyme in the TA muscle. Compared to WT muscle, CK activity is significantly reduced in the Capn3-deficient muscle (Fig. 5d). Concomitantly, we observed that the glycolytic activity (as indicated by LDH activity) was significantly increased in the Capn3-deficient muscles as compared to the WT muscles (Fig. 5e). Together, the above findings indicate that mitochondrial biogenesis and activity are compromised both in vivo and in vitro, and the Capn3-deficient muscle may be compensating for reduced mitochondrial activity by increased aerobic glycolytic activity.

\section{Effect of Capn3 deficiency on myoblast proliferation}

Since enhanced aerobic glycolysis is associated with increased cell proliferation [33], we examined if the reduced mitochondrial activity and seemingly greater aerobic glycolysis in
Capn3-deficient cells lead to increased proliferation. To monitor the rate and extent of cell proliferation for Capn3deficient and WT myoblasts, we made use of the CFSE dilution approach (Fig. 6a) as well as cell counting (Fig. 6b). Both these approaches showed that the extent of proliferation of Capn3-deficient myoblasts was higher than the WT myoblasts (Fig. 6a, b). This observation shows that in vitro, Capn3-deficient myoblasts are more reliant on aerobic glycolysis for their energy provision, which may account for their enhanced ability to proliferate.

\section{Effect of the PPAR-delta agonist, GW501516, on Capn3- deficient mice}

In view of the mitochondrial deficit and its consequences on Capn3-deficient muscle, we examined if improving mitochondrial biogenesis could be beneficial. We treated Capn3-deficient mice with the PPAR-delta agonist, GW501516, which we have previously used to enhance mitochondrial biogenesis in the $\mathrm{mdx}$ mouse model [43]. First, we assessed the effect of this treatment on satellite cell activity in vivo by monitoring the expression of Pax7 and MyoD mRNA. We observed an increased expression of Pax7 (80\%) and MyoD (160\%) mRNA in GW501516-treated Capn3-deficient mice (Fig. $6 c, d)$, suggesting that increases in mitochondrial biogenesis increased the muscle satellite cell pool in vivo.

\section{Effect of the PPAR-delta agonist GW501516 on muscle function in Capn3-deficient mice}

Treatment with PPAR-delta agonist, GW501516, increased the EDL mass relative to body weight but 
Table 1 Differentially expressed mitochondrial metabolic genes in Capn3 ${ }^{-/-}$myoblasts

\begin{tabular}{|c|c|c|}
\hline Symbol & Entrez Gene Name & Function \\
\hline ATP5C1 & ATP synthase, $\mathrm{H}+$ transporting, mitochondrial F1 complex, gamma polypeptide 1 & transporter \\
\hline ATPAF2 & ATP synthase mitochondrial F1 complex assembly factor 2 & other \\
\hline SLC2A12 & solute carrier family 2 (facilitated glucose transporter), member 12 & transporter \\
\hline SLC37A4 & solute carrier family 37 (glucose- 6 -phosphate transporter), member 4 & transporter \\
\hline PFKFB3 & 6-phosphofructo-2-kinase/fructose-2,6-biphosphatase 3 & kinase \\
\hline OXGR1 & oxoglutarate (alpha-ketoglutarate) receptor 1 & G-protein coupled receptor \\
\hline LOC620306 & similar to Glyceraldehyde-3-phosphate dehydrogenase (GAPDH) & other \\
\hline GSK3A & glycogen synthase kinase 3 alpha & kinase \\
\hline GFPT1 & glutamine--fructose-6-phosphate transaminase 1 & enzyme \\
\hline ALDOC & aldolase $\mathrm{C}$, fructose-bisphosphate & enzyme \\
\hline AlFM3 & apoptosis-inducing factor, mitochondrion-associated, 3 & enzyme \\
\hline SLC2A13 & solute carrier family 2 (facilitated glucose transporter), member 13 & transporter \\
\hline MRPL21 & mitochondrial ribosomal protein L21 & other \\
\hline GYS2 & glycogen synthase 2 (liver) & enzyme \\
\hline UCP3 & uncoupling protein 3 (mitochondrial, proton carrier) & transporter \\
\hline UCP3 & uncoupling protein 3 (mitochondrial, proton carrier) & transporter \\
\hline FBP2 & fructose-1,6-bisphosphatase 2 & phosphatase \\
\hline DLST & dihydrolipoamide S-succinyltransferase (E2 component of 2-oxo-glutarate complex) & enzyme \\
\hline FOXRED2 & FAD-dependent oxidoreductase domain containing 2 & other \\
\hline MRPL35 & mitochondrial ribosomal protein L35 & other \\
\hline A4GALT & alpha 1,4-galactosyltransferase & enzyme \\
\hline MTCH1 & mitochondrial carrier homolog 1 (C. elegans) & other \\
\hline ATP5S & ATP synthase, $\mathrm{H}+$ transporting, mitochondrial Fo complex, subunit s (factor $B$ ) & transporter \\
\hline ACAA1 & acetyl-CoA acyltransferase 1 & enzyme \\
\hline COX7A2L & cytochrome $\mathrm{c}$ oxidase subunit VIla polypeptide 2 like & enzyme \\
\hline POR & P450 (cytochrome) oxidoreductase & enzyme \\
\hline Timm8a2 & translocase of inner mitochondrial membrane 8 homolog a2 (yeast) & other \\
\hline ACAT2 & acetyl-CoA acetyltransferase 2 & enzyme \\
\hline $\operatorname{cox} 412$ & cytochrome c oxidase subunit IV isoform 2 (lung) & enzyme \\
\hline OGFOD2 & 2-oxoglutarate and iron-dependent oxygenase domain containing 2 & other \\
\hline ISCA2 & iron-sulfur cluster assembly 2 homolog (S. cerevisiae) & other \\
\hline G6PC & glucose-6-phosphatase, catalytic subunit & phosphatase \\
\hline MRPS27 & mitochondrial ribosomal protein S27 & other \\
\hline PPARG & peroxisome proliferator-activated receptor gamma & ligand-dependent nuclear receptor \\
\hline SLC2A6 & solute carrier family 2 (facilitated glucose transporter), member 6 & transporter \\
\hline NQO1 & $\mathrm{NAD}(\mathrm{P}) \mathrm{H}$ dehydrogenase, quinone 1 & enzyme \\
\hline HARS2 & histidyl-tRNA synthetase 2 , mitochondrial (putative) & enzyme \\
\hline SLC25A21 & solute carrier family 25 (mitochondrial oxodicarboxylate carrier), member 21 & transporter \\
\hline ATP5S & ATP synthase, $\mathrm{H}+$ transporting, mitochondrial Fo complex, subunit s (factor $B$ ) & transporter \\
\hline NDUFS1 & NADH dehydrogenase (ubiquinone) Fe-S protein $1,75 \mathrm{kDa}$ (NADH-coenzyme $\mathrm{Q}$ reductase) & enzyme \\
\hline CPT1B & carnitine palmitoyltransferase $1 \mathrm{~B}$ (muscle) & enzyme \\
\hline ATPAF1 & ATP synthase mitochondrial F1 complex assembly factor 1 & other \\
\hline Tmed11 & transmembrane emp24 protein transport domain containing & transporter \\
\hline MRPS14 & mitochondrial ribosomal protein $\mathrm{S} 14$ & other \\
\hline PCK2 & phosphoenolpyruvate carboxykinase 2 (mitochondrial) & kinase \\
\hline OXSM & 3-oxoacyl-ACP synthase, mitochondrial & kinase \\
\hline Acaa1b & acetyl-Coenzyme $\mathrm{A}$ acyltransferase 1B & enzyme \\
\hline HSPA13 & heat shock protein $70 \mathrm{kDa}$ family, member 13 & other \\
\hline TMEM59L & transmembrane protein 59 -like & other \\
\hline SQRDL & sulfide quinone reductase-like (yeast) & enzyme \\
\hline MRPL19 & mitochondrial ribosomal protein L19 & other \\
\hline MDH1B & malate dehydrogenase 1B, NAD (soluble) & enzyme \\
\hline PPARGC1A & peroxisome proliferator-activated receptor gamma, coactivator 1 alpha & transcription regulator \\
\hline TOMM22 & translocase of outer mitochondrial membrane 22 homolog (veast) & transporter \\
\hline
\end{tabular}

did not change soleus mass relative to body weight (Fig. 7a). Next, we analyzed muscle function, which showed that treatment with GW501516 did not lead to a change in the specific force of the soleus muscle but reduced the EDL-specific force (Fig. 7b). The twitch-to-tetanus force ratios are higher in EDL than in soleus but showed no difference between the vehicle- and drug-treated EDL or soleus muscles (Fig. 7c). We found that GW treatment leads to slower time-to-peak twitch tension (TTP) of the EDL muscle but did not reach statistical significance (Fig. 7d). We did not see differences between the groups for half-relaxation time because of the small sample size and variation (Fig. 7e). EDL maximal force relative to baseline decreased with time but did not show differences between vehicle- and drug-treated mice (Fig. 7f). On the other hand, the soleus muscle showed more fatigue resistance in treated mice compared to vehicle reaching statistical difference at a 3-min time point (Fig. $7 \mathrm{~g}$ ).

We observed that the level of CK in the serum was significantly decreased in the GW501516-treated mice (Fig. 8a), suggesting a decrease in muscle leakage and damage. Drug- treated mice also showed a significant improvement in the Rotarod activity (Fig. 8b), suggesting that these mice exhibit better movement coordination after treatment. The openfield activity measurement demonstrated an overall increase in parameters such as horizontal distance (Fig. 8c), total distance (Fig. 8d), movement number (Fig. 8e), and movement time (Fig. 8f), GW501516-treated mice suggesting increase in activity after treatment.

\section{Effect of muscle injury-induced activation of mitochondrial activity in Capn3-deficient muscle}

Reduced mitochondrial and calpain activity compromises muscle cell membrane repair [34, 35, 44-46]. Our findings that Capn3-deficient mice show mitochondrial dysfunction and treatment with GW501516 decreases serum CK levels suggest that mitochondrial deficit may underlie poor myofiber repair and addressing this deficit improves myofiber membrane repair. Thus, we evaluated the membrane repair capacity and its dependence on mitochondria activity in the Capn3-deficient muscle cells. Response to focal laser injury in isolated EDL fibers from Capn3-deficient mice (Fig. 9, bottom panels at 0 , 


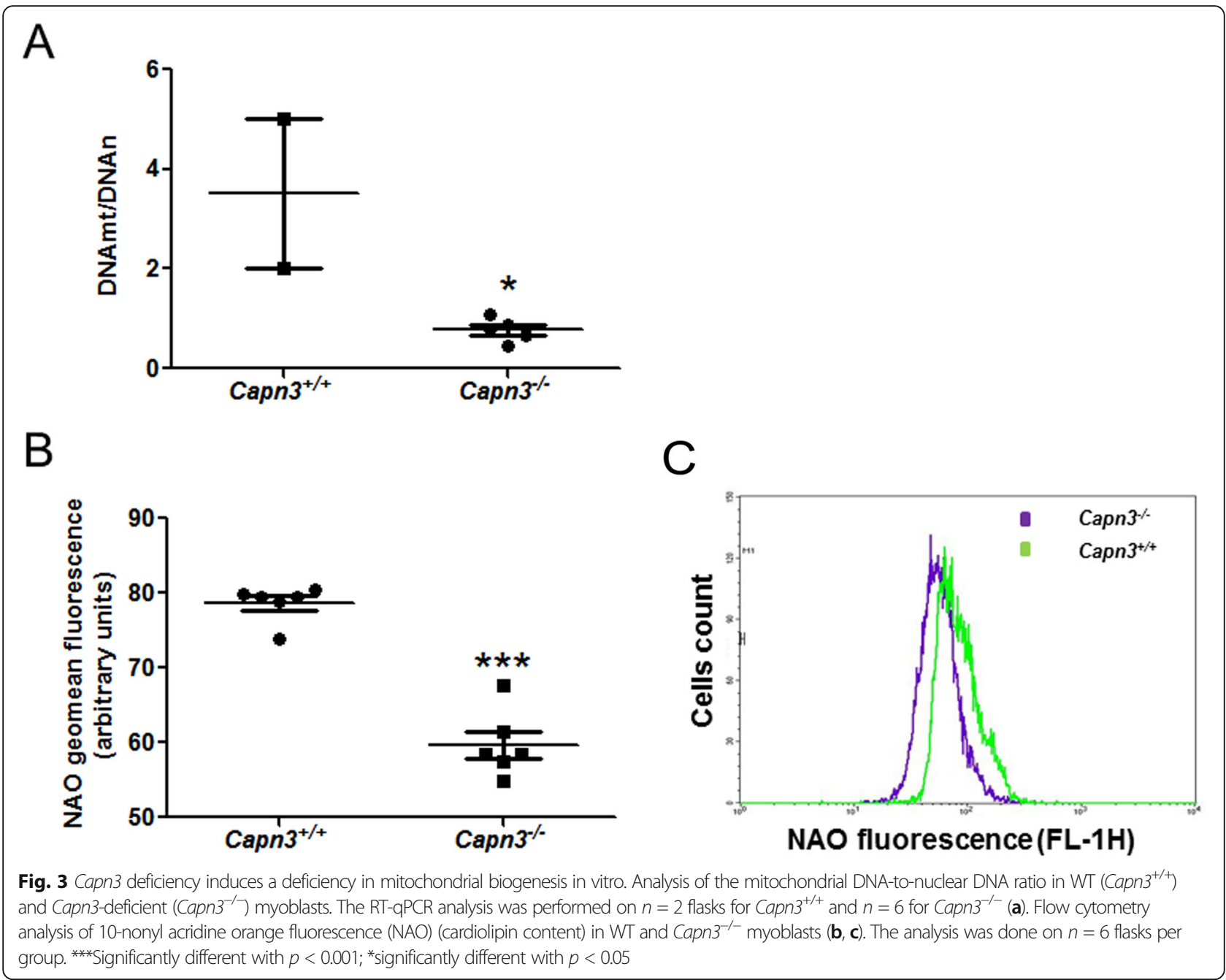

60 , and $240 \mathrm{~s}$ ) at 3 months of age showed increased dye compared to EDL fibers from WT mice (Fig. 9, top panels at 0,60 , and $240 \mathrm{~s}$ ).

We next evaluated to see if this deficit is also present in other muscle types. Muscle fibers from Capn3-deficient mice showed reduced ability to repair from focal laser injury, resulting in increased entry of membrane impermeant dye FM 1-43 in the intact biceps brachii (Fig. 10a), soleus (Fig. 10b), and EDL (Fig. 10c) muscles, as well as in the isolated EDL fibers (Fig. 10d). Next, we confirmed that disruption of mitochondrial membrane potential $(\Delta \Psi)$ with the protonophore CCCP $(4 \mu \mathrm{M})$ compromised repair of focally injured WT EDL myofibers as shown previously [34, 35] (Fig. 10e). We next examined if enhancing the mitochondrial activity improves repair of Capn3-deficient myofibers. To enhance mitochondrial activity, isolated Capn3-deficient EDL myofibers were treated for $30 \mathrm{~min}$ with $100 \mathrm{mM}$ pyruvate. This increased mitochondrial membrane potential as monitored by the membrane potential-sensitive dye
DiOC6 (Fig. $10 \mathrm{~g}$ ). This increase in mitochondrial activity resulted in the enhanced ability of the injured Capn3-deficient myofibers to repair (Fig. 10f). These results demonstrate poor repair of the Capn3-deficient myofibers is due in part to the mitochondrial deficit, and increasing mitochondrial activity enables improved repair of the Capn3-deficient myofibers.

\section{Discussion}

In the present study, we demonstrated that the muscles lacking CAPN3 have a deficiency in mitochondrial biogenesis and mitochondrial activity, which results in the poor repair of injured myofiber sarcolemma. We tested a potential therapeutic approach in vivo-an activator of mitochondrial biogenesis (GW501516), which showed benefits that hold the promise of addressing the cellular deficits caused by the lack of CAPN3.

Since culturing primary myoblasts is prone to a significant difference between different primary isolates, and since siRNA knockdown in stable cell lines results in 


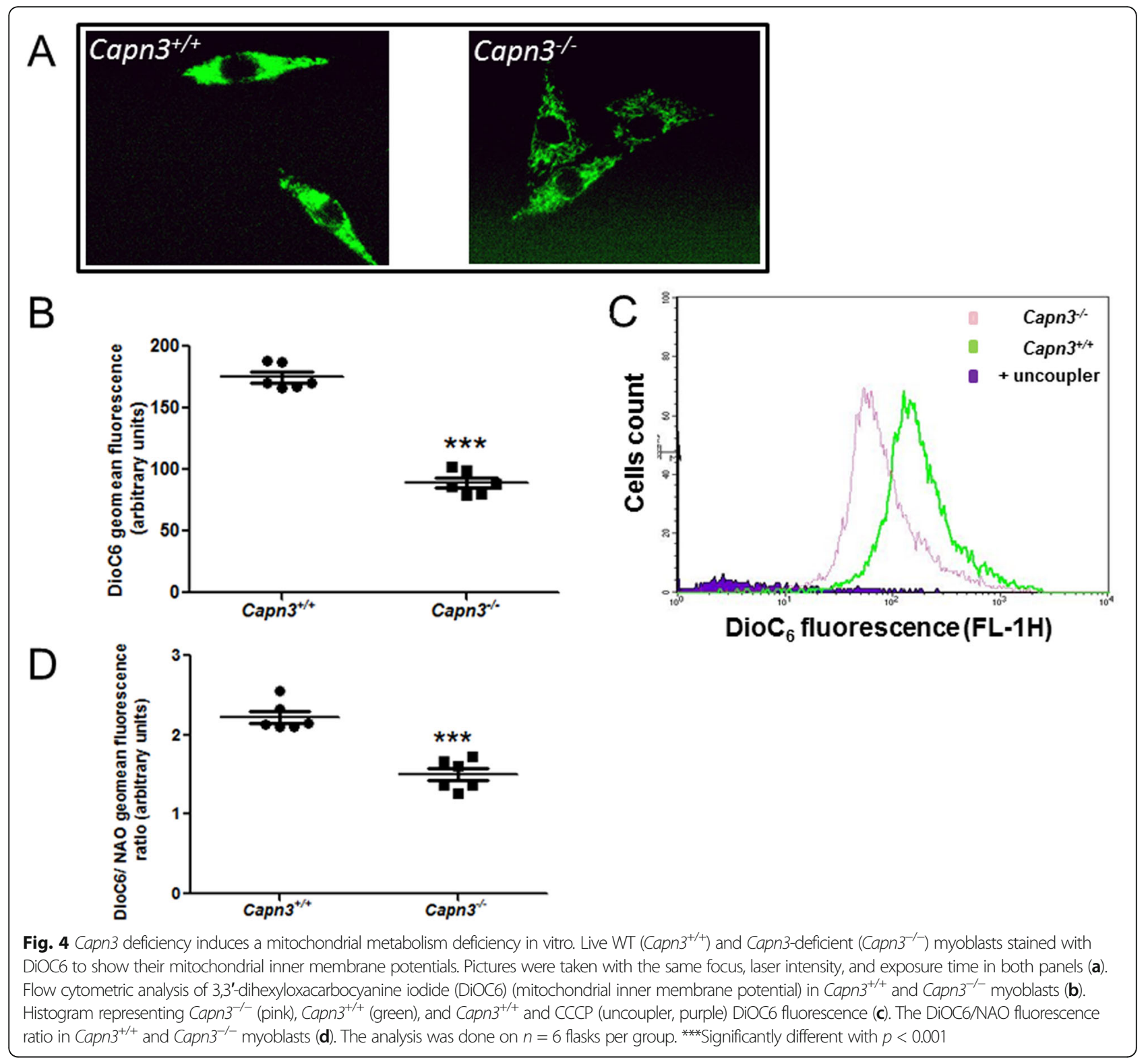

significant variability between individual cells, we generated primary myoblast cells from Capn3-deficient mice that stably express SV40 large T antigen under an IFN $\gamma$ regulated promoter [23]. Through this approach, we produced stable cultures of Capn3-deficient primary myoblasts. This facilitated the reproducible investigation of the effects of Capn3 deficiency in vitro. In order to study the global gene expression changes in Capn3 deficiency in an unbiased manner, we utilized a BeadChip array, analyzing the expression of 45,000 genes in Capn3-deficient myoblasts and myotubes. Expression profiling studies indicated abnormalities in lipid and mitochondrial metabolism. These findings were validated in vitro by performing physiological analysis of mitochondrial (cardiolipin) content and the mtDNA-to-
nDNA ratio in living cells, which were reduced in the absence of CAPN3. These findings indicate that Capn3 deficiency causes a decrease in mitochondrial mass in the muscle cells. We also observed a reduction in mitochondrial membrane potential in the Capn3-deficient muscle cells. Analysis of the ratio between mitochondrial content and mitochondrial activity revealed that the mitochondrial defect was not only due to the defect in biogenesis but also in the mitochondrial activity. These data are in agreement with the results of our gene expression profiling experiments, in which we found more than 50 genes related to mitochondrial biogenesis and mitochondrial metabolism to be downregulated in the Capn3-deficient muscle cells. While these differences do not provide an insight into the molecular mechanisms 
A

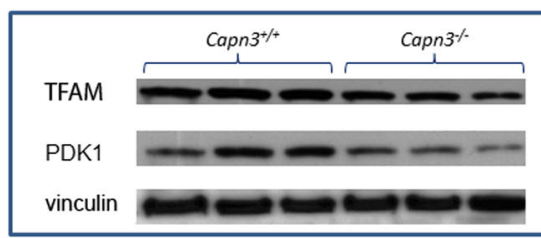

B

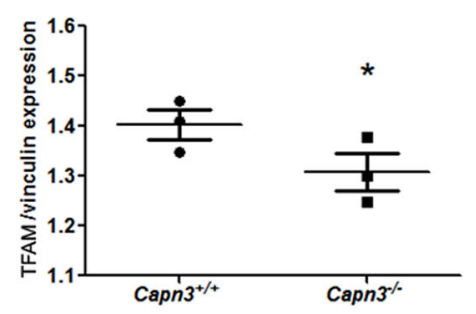

C

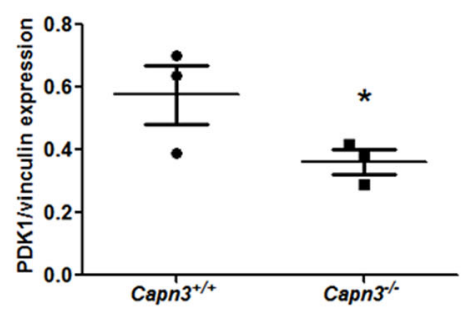

D

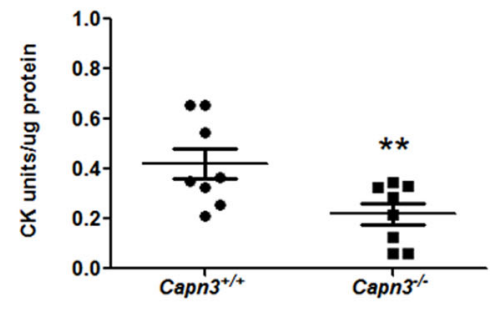

E

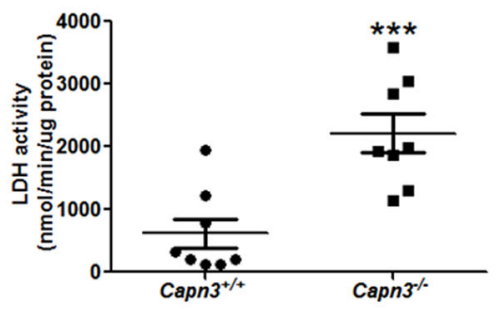

Fig. 5 Capn3 deficiency induces mitochondrial deficiency in vivo. Western blot of vinculin (control), TFAM, and PDK1 in the TA muscle lysates from WT

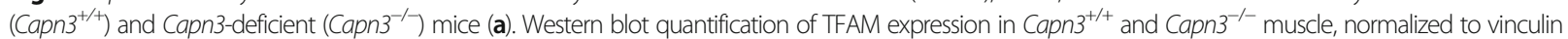
expression $(n=3)(\mathbf{b})$. Western blot quantification of PDK1 expression in the Capn $3^{+/+}$and $\mathrm{Capn}^{-1-}$ muscle, normalized to vinculin expression $(n=3)(\mathbf{c})$. Creatine kinase (CK) activity in the Capn $3^{+/+}$and $\mathrm{Capn}^{-/-} \mathrm{TA}$ muscle, normalized to protein concentration $(n=8)(\mathbf{d})$. LDH activity measured in the Capn3 $3^{+/+}$ and $\mathrm{Capn}^{-/-}$TA muscle, normalized to protein concentration $(n=8)(\mathbf{e})$. ${ }^{* *}$ Significantly different with $p<0.001$; ${ }^{*}$ significantly different with $p<0.01$; *significantly different with $p<0.05$

A

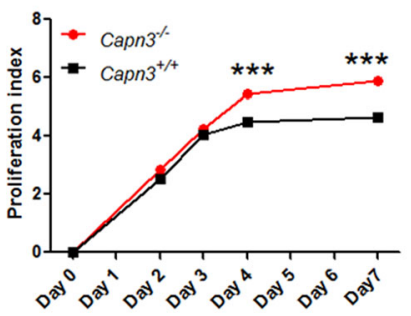

C

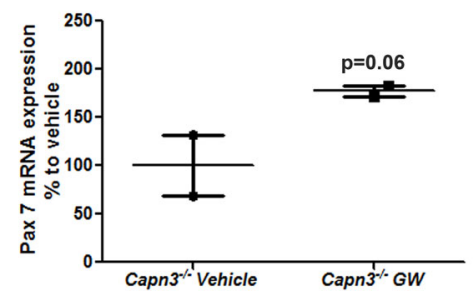

B

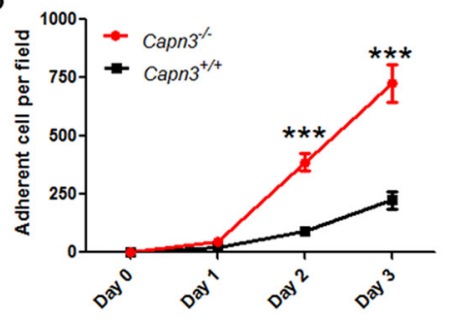

D

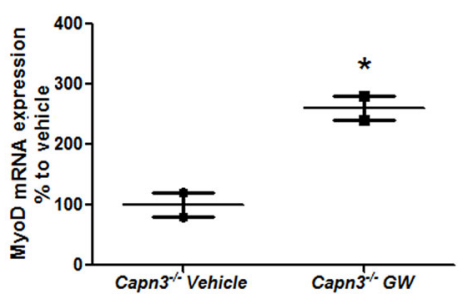

Fig. 6 Myoblast proliferation behavior and effect of mitochondrial activity improvement on satellite cell markers. Proliferation kinetics of WT $\left(\mathrm{Capn}^{+/+}\right)$and Capn3-deficient $\left(\mathrm{Capn}^{-/-}\right)$myoblasts analyzed through flow cytometry by either CFSE fluorescence decrease $(n=4)(\mathbf{a})$ or manual counting $(n=5)(\mathbf{b})$. Expression of Pax7 mRNA (c) and MyoD mRNA (d) after 4 weeks of GW501516 treatment in the quadriceps muscle from 7-month-old Capn3 ${ }^{-1-}$ mice $(n=2)$. ${ }^{* *}$ Significantly different with $p<0.001$; ${ }^{*}$ significantly different with $p<0.05$ 

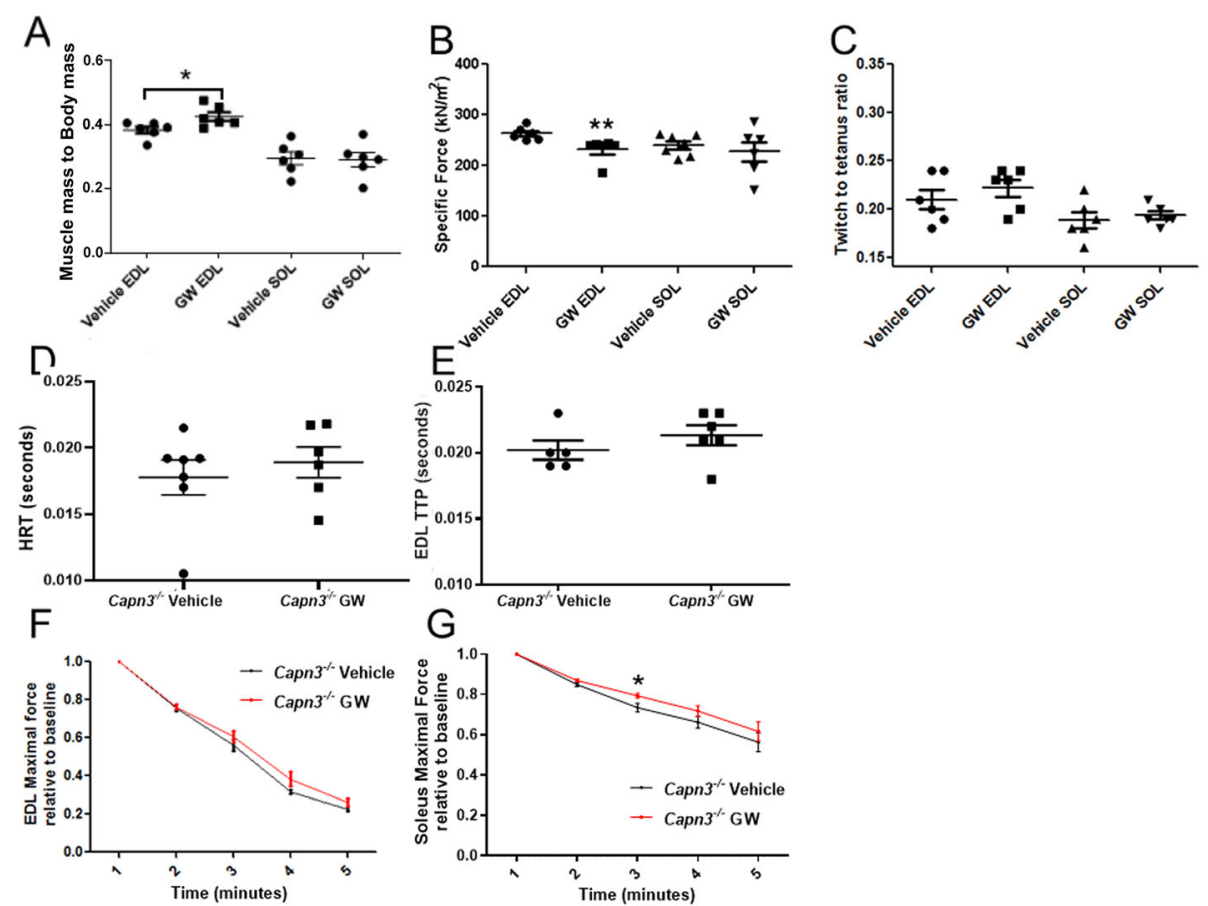

Fig. 7 The effect of enhanced mitochondrial activity on muscle phenotype in 9-month-old Capn3-deficient mice. EDL and soleus muscle mass (a) specific force in Capn3-deficient (Capn3 $3^{-/-}$) mice treated with GW501516 (GW) or vehicle (b). Twitch-to-tetanus ratio of EDL and SOL in Capn3 ${ }^{-/-}$ mice treated with GW or vehicle (c). Half-relaxation time (HRT) (s) (d), time to peak twitch tension (TTP) (s), of EDL muscle (e) of GW- or vehicletreated mice. Maximal force relative to baseline for the EDL $(\mathbf{f})$ and soleus $(\mathbf{g})$ muscles in $\mathrm{Capn}^{-1-}$ mice treated with $\mathrm{GW}$ or vehicle. The force is expressed relative to the maximal force at the beginning of the experiment. Significance indicated difference at $3 \mathrm{~min}$

that link lipid and mitochondrial abnormalities to CAPN3 deficiency, we did find that Capn3-deficient mice exhibit a decreased expression of TFAM, the mitochondrial transcription factor that activates mitochondrial transcription and participates in mitochondrial genome replication. Capn3-deficient muscle also showed reduced PDK1 and creatine kinase levels, while the LDH activity was increased, all of which corroborate the mitochondrial dysfunction. Our findings are also supported by previous analyses that have identified structural and biochemical abnormalities in Capn3-deficient skeletal muscle mitochondria, which lead to an energy deficit and enhanced ROS levels in the muscles in vivo [21]. While an injury-induced acute increase in mitochondrial ROS is beneficial for membrane repair, we have shown that chronic high levels of mitochondrial ROS inhibit membrane repair [34]. This could be the basis for the poor sarcolemmal repair we observe in the Capn3-deficient myofibers.

To understand how mitochondrial abnormalities in Capn3-deficient cells contribute to the disease pathogenesis in LGMD2A, we studied the growth and differentiation of myoblasts. Increased aerobic glycolysis we observed in Capn3-deficient cells led to enhanced proliferation of these cells compared to the WT myoblasts. Our observation that myoblast proliferation is enhanced by CAPN3 deficit mirrors previous findings that CAPN3 overexpression promotes the renewal of $\mathrm{C} 2 \mathrm{C} 12$ myoblast through inhibition of MyoD [47]. In contrast, Capn3-deficient $\mathrm{C} 2 \mathrm{C} 12 \mathrm{~s}$ have a reduced ability to return to quiescence (the $G_{0}$ phase of the cell cycle) after activation, suggesting the stimulation of the cell cycle when CAPN3 is defective. Increased proliferation index for Capn3-deficient muscle cells corroborates the putative link between CAPN3 and the transition from $G_{0}$ (quiescence) to $G_{1}$ (cell cycle entrance) in muscle cells. We have now demonstrated that improving mitochondrial biogenesis in 7-month-old Capn3-deficient mice increases their expression of MyoD and Pax7 mRNAs in muscle, suggesting that mitochondrial activity improves satellite cell activation but also stimulates the renewal of these cells in vivo.

PPAR $\delta$, a transcription factor that regulates mitochondrial biogenesis, has been shown to participate in the renewal of the satellite cell pool [48]. When PPAR $\delta$ is shut down in the muscles, even at birth, the animals display no difference in body weight, muscle size, or muscle composition, but later, they develop metabolic syndrome and have fewer satellite cells than their WT littermates. Furthermore, the PPAR $\delta$-deficient muscles show impaired recovery from cardiotoxin-induced injury [48]. In addition to these previously reported changes, we also 

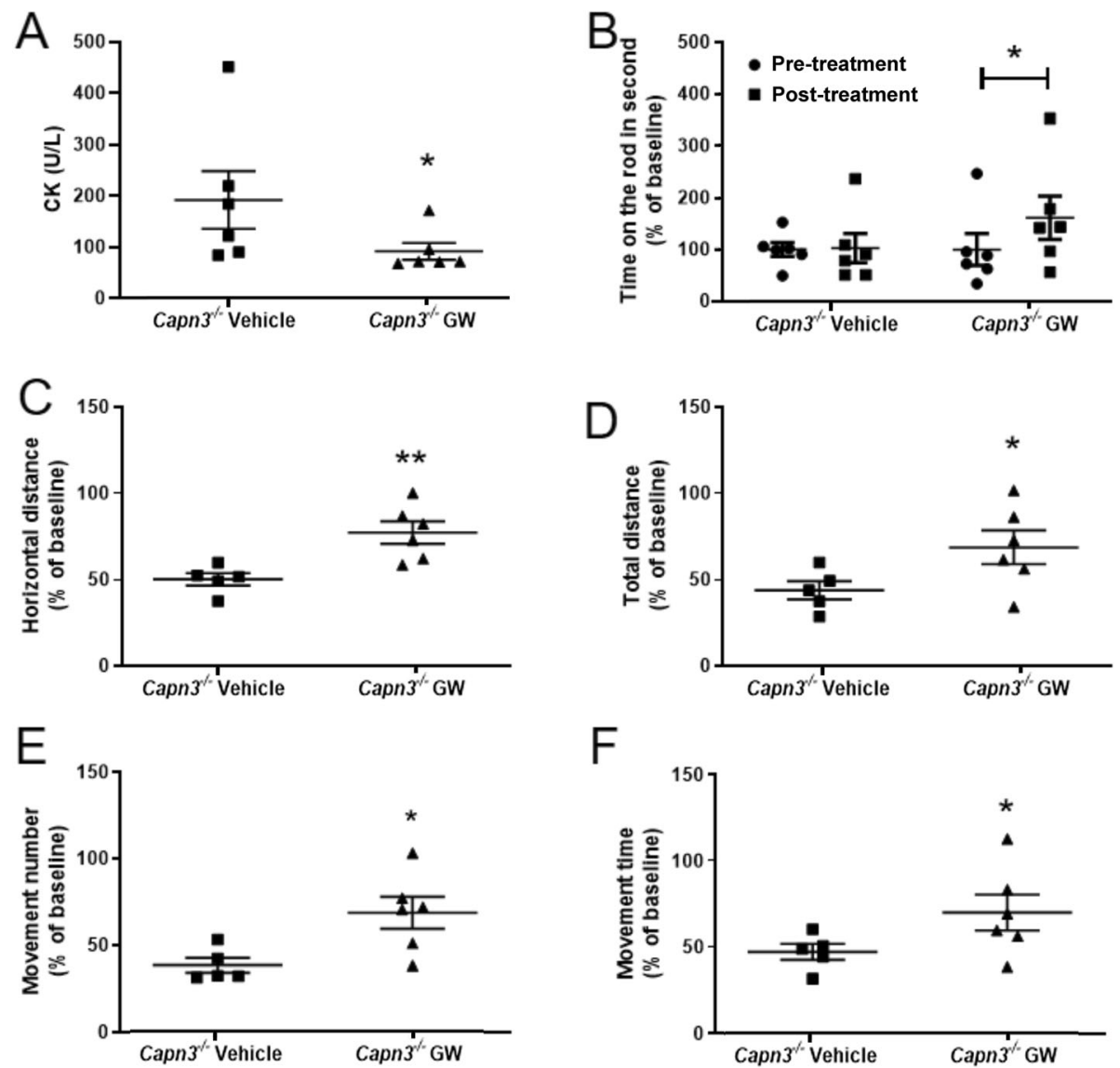

Fig. 8 Biochemical and behavioral assessments after GW501516 treatment. Creatine kinase (CK) activity in the blood serum extracted by heart puncture immediately after euthanasia from $\mathrm{Capn}^{-1-}$ mice treated with GW or vehicle (a). Time on the Rotarod in seconds before and after treatment of $\mathrm{Capn}^{-1-}$ mice with GW or vehicle (b). Behavioral activity measurements such as horizontal distance (c), total distance (d), movement number (e), and movement number (f) were used to assess the overall behavioral activity. Experiments were done with $n=6$ mice per group. **Significantly different with $p<0.01$; ${ }^{*}$ significantly different with $p<0.05$

found that improving mitochondrial function in Capn3deficient mice by using a PPAR $\delta$ agonist increased resistance to fatigue in the soleus muscle, increased performance of mice on the Rotarod and open-field activity, and reduced serum CK levels within 4 weeks of treatment. This treatment also reduced EDL-specific force closer to soleus muscle measurements but did not induce significant benefit for reducing EDL fatigue. These data are consistent with the observations derived from genetic overexpression of PPAR $\delta$ in mice [49]. PPAR $\delta$ overexpression is sufficient to induce an oxidative muscle phenotype characterized by increased type I muscle fibers and enhanced fatigue resistance. Because EDL is more of a fast-twitch muscle, our observation of reduced specific force may indicate that it was beginning to take on more characteristics of a slower twitch (type I) muscle. With just a 1-month treatment, it is not surprising that we see some tendency, but not a complete switch towards this phenotype. The reduced serum CK levels found in the Capn3-deficient mice suggest that muscle damage in these mice is reduced in response to increased mitochondrial activity. It is pertinent to note that future dose-ranging experiments with an appropriate sample size of Calpain3-deficient and Calpain3sufficient mice would need to provide strong evidence to these preliminary observations.

Previously, we showed that optimal mitochondrial functioning is required for sarcolemmal repair, and defects in this lead to multiple muscle diseases [35-38]. Therefore, we investigated the effect of mitochondrial deficit on sarcolemmal repair in the Capn3-deficient mice. Previous studies using freshly isolated flexor digitorum brevis (FDB) myofiber in the Capn3-deficient mice found no difference in the rate of FM 1-43 dye entry following focal sarcolemmal injury [50]. However, using intact biceps brachii, soleus, and EDL muscles as well as isolated EDL muscle fibers (adhered to Matrigel substrate) from Capn3-deficient mice, we found that a lack of CAPN3 compromised the ability of the injured myofibers to repair a focal injury (Fig. 9). The difference 


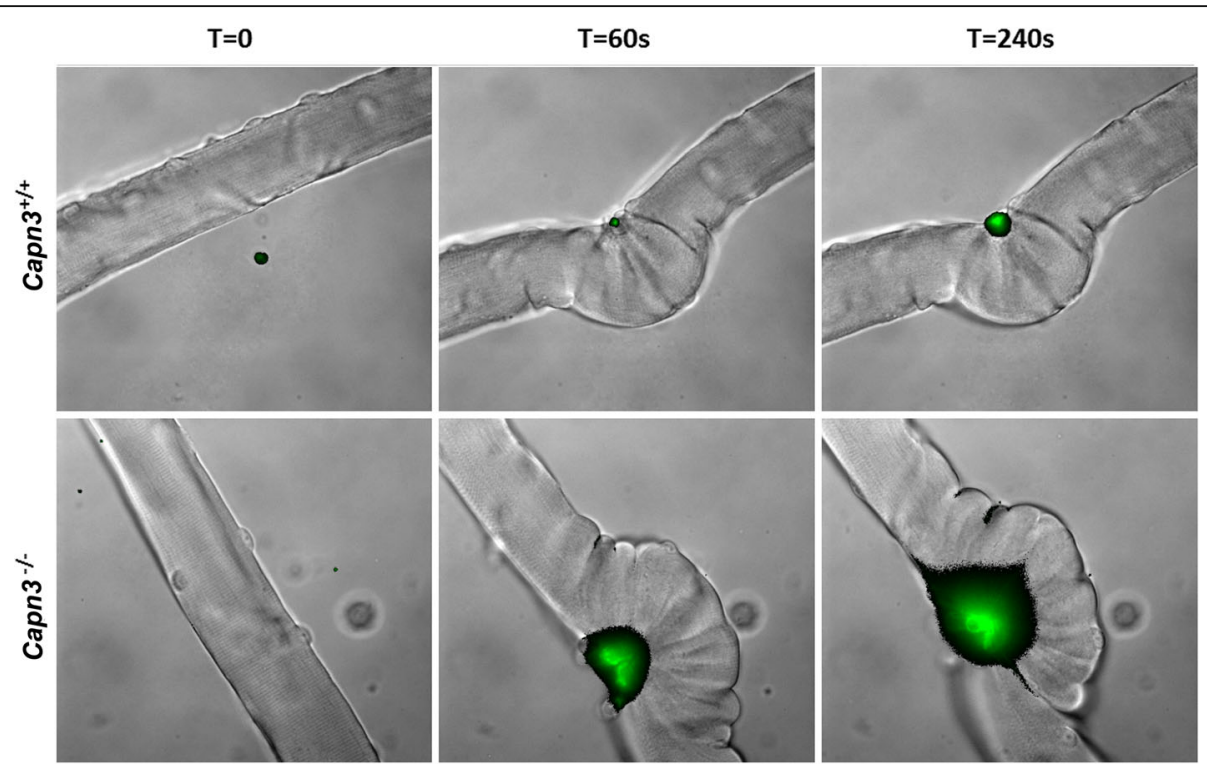

Fig. 9 Membrane repair deficits in Capn3-deficient muscle after laser injury. Response to focal laser injury in isolated EDL fibers from WT $\left(\left(\mathrm{Capn}^{+/+}\right)\right.$top panels at 0, 60, and $\left.240 \mathrm{~s}\right)$ or Capn3-deficient ((Capn3 $\left.{ }^{-/-}\right)$bottom panels at 0, 60, and $\left.240 \mathrm{~s}\right)$ at 3 months of age. Overlay of the FM 1-43 dye fluorescence (green) on the bright-field (greyscale) image is shown

in the two observations may reflect the differential effects of CAPN3 deficit that we have observed in the repair ability of the different muscles (EDL > biceps brachii > soleus). In addition, our observations that the repair deficit is most pronounced when the myofibers are injured in intact tissue in the context of proper extracellular matrix support, rather than in isolated myofibers, may be a source of difference between in vivo physiological injury to skeletal myofibers vs. experimental as has been examined previously [50]. The poor sarcolemmal repair in Capn3-deficient mice that we observed corresponds to the repair deficit we observed in WT EDL myofibers where the mitochondria were depolarized by CCCP treatment. This implicates mitochondrial dysfunction in the poor sarcolemmal repair seen in the Capn3-deficient muscle. This explanation is substantiated by our observation that an increase in mitochondrial activity in Capn3-deficient EDL muscle produced by the use of pyruvate not only improved the mitochondrial membrane potential (assessed by DiOC6 fluorescence) but also significantly improved the ability of the Capn3-deficient myofibers to heal from laser injury. We have previously demonstrated that increased energy production through the tricarboxylic acid (TCA) cycle is not required for mitochondria-mediated cell membrane repair [34]. Thus, pyruvate-induced improvement in Capn3-deficient myofiber repair increase in mitochondrial activity may be mediated by improved mitochondrial calcium homeostasis due to the normalization of the mitochondrial membrane potential deficit in the Capn3-deficient muscle. Such a mode of action is supported by our recent demonstration that dysregulation of mitochondrial calcium homeostasis in the skeletal muscle compromises myofiber repair [38]. Independent of the direct mode of action, our data offers support to an important role of mitochondria in the Capn3-deficient muscle by way of impairing sarcolemmal repair.

Mitochondrial abnormalities have been described in other muscle diseases such as collagen VI-related myopathies [51, 52], muscular dystrophy due to choline kinase beta (CHKB) gene mutations [53], myositis [37], and Duchenne muscular dystrophy [36]. We and others have previously demonstrated that addressing mitochondrial abnormalities in $m d x$ mice can reduce muscle pathology and improve muscle function [43, 54-58]. Thus, our observations suggest an overlap in therapies for muscular dystrophies that improve mitochondrial metabolism.

\section{Conclusion}

This study demonstrates that CAPN3 deficiency in the skeletal muscle is associated with abnormal mitochondria biogenesis and activity. We provide evidence that this phenotype is associated with a dysregulated myoblast proliferation. Mitochondrial impairment also reduces the repair ability of the Capn3-deficient myofibers. Taken together, our data identify a role for mitochondrial abnormality as a central contributor to the myofiber and muscle repair pathologies observed due to CAPN3 deficit. By using therapeutic approaches to target the mitochondrial deficit in vivo, we offer a proof-of-concept demonstration of novel drug targets 


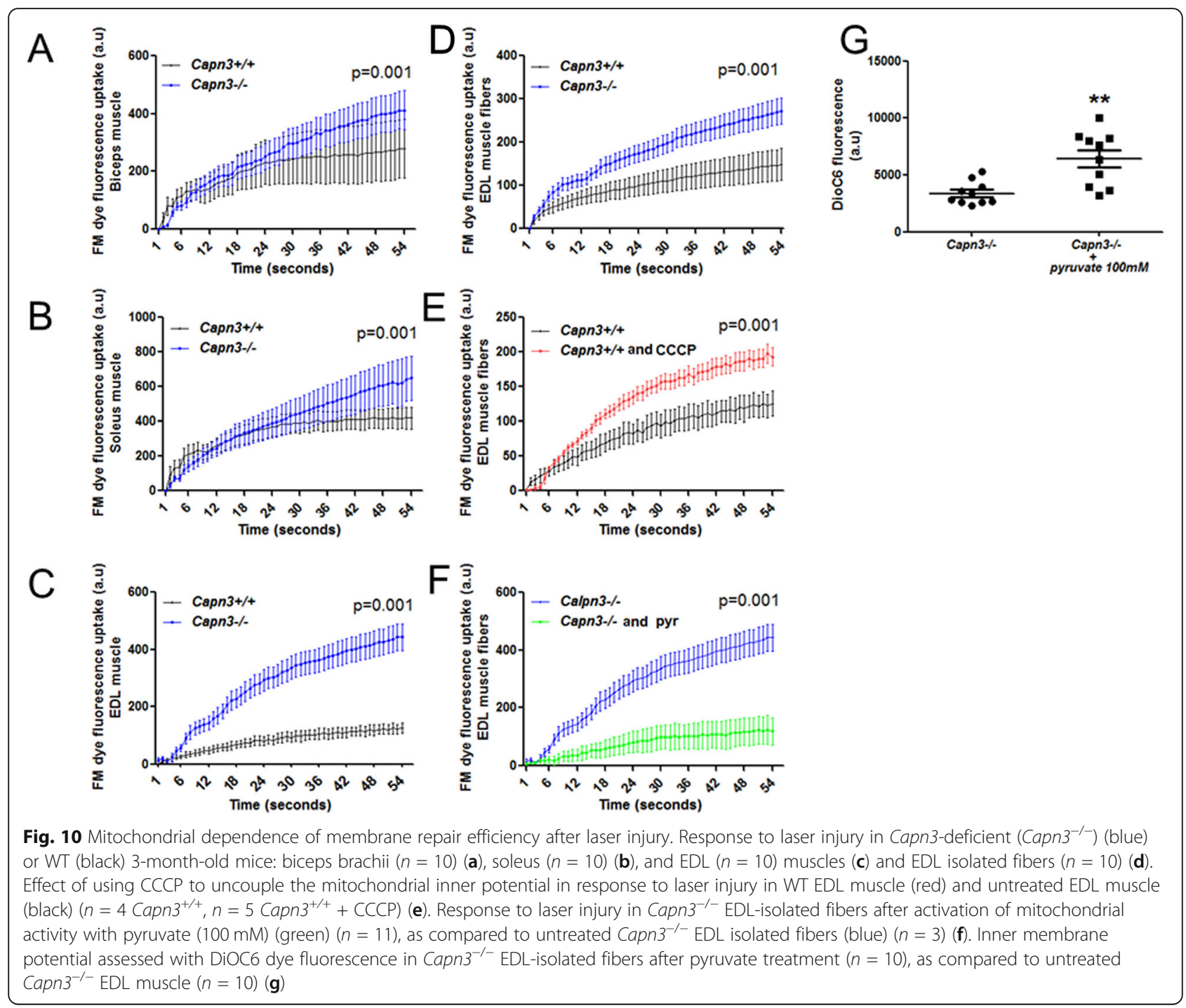

and candidates to treat Capn3 deficiency in the skeletal muscle.

\section{Supplementary Information}

The online version contains supplementary material available at https://doi. org/10.1186/s13395-020-00254-1.

Additional file 1: Supplemental Figure 1. Gene expression profiling of Capn3-deficient vs. WT myotubes with an Illumina BeadChip array. Dendrogram results attesting the good clustering of Capn3-deficient $\left(\mathrm{Capn}^{--1}\right)$ myotube samples when compared to corresponding WT $\left(\mathrm{Capn}^{+/+}\right)$muscle cells (A). Ingenuity pathway analysis demonstrating changes in mitochondrial biogenesis, lipid metabolism, and protein transport in myotubes. Pink indicates an upregulation and green indicates a downregulation of the specific genes in $\mathrm{Capn}^{-1-}$ myotubes compared to $\mathrm{Capn}^{+/+}$myotubes (B). Three different samples were used per group. cRNA was synthesized from $250 \mathrm{ng}$ of total RNA for each sample. Gene pathways were prepared by ingenuity pathways analysis according to a gene list based on the interaction of a gene candidate with a $p$ value of 0.001 and a fold increase $\geq 4$.
Additional file 2: FFold changes in WT and calpain-3 deficient myoblasts and myotubes.

\section{Abbreviations}

LGMD2A: Limb-girdle muscular dystrophy type 2A; calpain-3: Human gene: CAPN3; mouse gene: Capn3; protein: CAPN3; H2KPM: H2K proliferation medium; IFN- - : Interferon- $\gamma ;$ mtDNA: Mitochondrial DNA; nDNA: Nuclear DNA; $\Delta \psi$ : Inner membrane potential; NAO: 10-Nonyl acridine orange; DiOC6: 3,3'-Dihexyloxacarbocyanine iodide; H2DFCDA: 2',7'-

Dichlorodihydrofluorescein diacetate; WT: Wild-type; CK: Creatine kinase; FM 1-43: N-(3-triethylammoniumpropyl)-4-(4-(dibutylamino)styryl)yridinium dibromide

\section{Acknowledgements}

We acknowledge Dr. Melissa Spencer for providing breeding pairs of Capn3deficient mice. We thank Dr. Deborah McClellan for the editorial assistance.

\section{Authors' contributions}

VEJ conceived the project idea, performed the experiments, analyzed the data, and wrote much of the manuscript. JMP and JKL analyzed the data and contributed to the writing of the manuscript. JHV, JB, KU, HKJ, AD, AP, and QY performed the experiments and analyzed the data. KN conceived 
the project, analyzed the data, and contributed to the writing of the manuscript. JKJ and AD proposed the cell repair work and helped VEJ to conduct these experiments and analyze the data. All authors approved the final manuscript.

\section{Authors' information}

Not applicable

\section{Funding}

This work was supported by the following: National Institutes of Health grants (1K26RR032082, 1P50AR060836-01, 1U54HD071601, 1R56NS097229-01, and 2R24HD050846-06), Department of Defense grants (W81XWH-11-1-0330, W81XWH-11-1-0782, W81XWH-10-1-0659, W81XWH-11-1-0809, and W81XWH-09-1-0599), a translational research grant from the Muscular Dystrophy Association, and Jarvis Crystal Ball fundraising to KN. This work was also supported by grants R01AR055686 (NIH/NIAMS) and U54HD090257 $(\mathrm{NIH} / \mathrm{NICHD})$ to JKJ.

\section{Availability of data and materials}

The datasets used and/or analyzed during the current study are available from the corresponding author on reasonable request. BeadChip Array data will be deposited in the GEO database.

\section{Ethics approval and consent to participate}

All mice were handled according to our Institutional Animal Care and Use Committee guidelines under approved protocols.

\section{Consent for publication}

Not applicable

\section{Competing interests}

The authors have no competing interest to declare.

\section{Author details}

'Center for Genetic Medicine Research, Children's National Research Institute, Children's National Hospital, Washington, D.C., USA. ${ }^{2}$ School of Exercise and Rehabilitation Sciences, The University of Toledo, Toledo, OH, USA.

${ }^{3}$ Department of Genomics and Precision Medicine, George Washington University School of Medicine and Health Sciences, Washington, D.C., USA. ${ }^{4}$ School of Pharmacy and Pharmaceutical Sciences, SUNY Binghamton University, PO Box 6000, Binghamton, NY 13902, USA

\section{Received: 19 March 2020 Accepted: 16 November 2020}

\section{Published online: 11 December 2020}

\section{References}

1. Goll DE, Thompson VF, Li H, Wei W, Cong J. The calpain system. Physiol Rev. 2003;83(3):731-801.

2. Sorimachi H, Imajoh-Ohmi S, Emori Y, Kawasaki H, Ohno S, Minami Y, et al. Molecular cloning of a novel mammalian calcium-dependent protease distinct from both $\mathrm{m}$ - and mu-types. Specific expression of the mRNA in skeletal muscle. J Biol Chem. 1989;264(33):20106-11.

3. Sorimachi H, Kinbara K, Kimura S, Takahashi M, Ishiura S, Sasagawa N, et al. Muscle-specific calpain, p94, responsible for limb girdle muscular dystrophy type 2A, associates with connectin through IS2, a p94-specific sequence. J Biol Chem. 1995;270(52):31158-62.

4. Beckmann JS, Spencer M. Calpain 3, the "gatekeeper" of proper sarcomere assembly, turnover and maintenance. Neuromuscul Disord. 2008;18(12):91321.

5. Dargelos E, Moyen C, Dedieu S, Veschambre P, Poussard S, Vuillier-Devillers $\mathrm{K}$, et al. Development of an inducible system to assess p94 (CAPN3) function in cultured muscle cells. J Biotechnol. 2002;96(3):271-9.

6. Richard I, Roudaut C, Marchand S, Baghdiguian S, Herasse M, Stockholm D, et al. Loss of calpain 3 proteolytic activity leads to muscular dystrophy and to apoptosis-associated IKBa/nuclear factor $\mathrm{KB}$ pathway perturbation in mice. J Cell Biol. 2000;151(7):1583-90.

7. Baghdiguian S, Martin M, Richard I, Pons F, Astier C, Bourg N, et al. Calpain 3 deficiency is associated with myonuclear apoptosis and profound perturbation of the $1 \mathrm{kBa} / \mathrm{NF}-\mathrm{kB}$ pathway in limb-girdle muscular dystrophy type 2A. Nat Med. 1999;5(5):503-11.
8. Richard I, Hogrel JY, Stockholm D, Payan CA, Fougerousse F, Calpainopathy Study G, et al. Natural history of LGMD2A for delineating outcome measures in clinical trials. Ann Clin Transl Neurol. 2016;3(4):248-65.

9. Fardeau M, Hillaire D, Mignard C, Feingold N, Feingold J, Mignard D, et al. Juvenile limb-girdle muscular dystrophy. Clinical, histopathological and genetic data from a small community living in the Reunion Island. Brain. 1996;119(Pt 1):295-308.

10. Dincer P, Leturca F, Richard I, Piccolo F, Yalnizoglu D, de Toma C, et al. A biochemical, genetic, and clinical survey of autosomal recessive limb girdle muscular dystrophies in Turkey. Ann Neurol. 1997:42(2):222-9.

11. Topaloglu H, Dincer P, Richard I, Akcoren Z, Alehan D, Ozme S, et al. Calpain-3 deficiency causes a mild muscular dystrophy in childhood. Neuropediatrics. 1997;28(4):212-6.

12. Schessl J, Walter MC, Schreiber G, Schara U, Muller CR, Lochmuller H, et al. Phenotypic variability in siblings with calpainopathy (LGMD2A). Acta Myol. 2008;27:54-8.

13. Pathak P, Sharma MC, Sarkar C, Jha P, Suri V, Mohd H, et al. Limb girdle muscular dystrophy type $2 \mathrm{~A}$ in India: a study based on semi-quantitative protein analysis, with clinical and histopathological correlation. Neurol India. 2010;58(4):549-54

14. Richard I, Broux O, Allamand V, Fougerousse F, Chiannilkulchai N, Bourg N, et al. Mutations in the proteolytic enzyme calpain 3 cause limb-girdle muscular dystrophy type 2A. Cell. 1995;81(1):27-40.

15. Groen EJ, Charlton R, Barresi R, Anderson LV, Eagle M, Hudson J, et al. Analysis of the UK diagnostic strategy for limb girdle muscular dystrophy 2A. Brain. 2007;130(Pt 12):3237-49.

16. Richard I, Roudaut C, Saenz A, Pogue R, Grimbergen JE, Anderson LV, et al. Calpainopathy-a survey of mutations and polymorphisms. Am J Hum Genet. 1999;64(6):1524-40.

17. Saenz A, Azpitarte M, Armananzas R, Leturcq F, Alzualde A, Inza I, et al. Gene expression profiling in limb-girdle muscular dystrophy 2A. PLoS One. 2008; 3(11):e3750.

18. Piluso G, Politano L, Aurino S, Fanin M, Ricci E, Ventriglia VM, et al. Extensive scanning of the calpain-3 gene broadens the spectrum of LGMD2A phenotypes. J Med Genet. 2005;42(9):686-93.

19. Kramerova I, Kudryashova E, Tidball JG, Spencer MJ. Null mutation of calpain 3 (p94) in mice causes abnormal sarcomere formation in vivo and in vitro. Hum Mol Genet. 2004:13(13):1373-88.

20. Tagawa K, Taya C, Hayashi Y, Nakagawa M, Ono Y, Fukuda R, et al. Myopathy phenotype of transgenic mice expressing active site-mutated inactive p94 skeletal muscle-specific calpain, the gene product responsible for limb girdle muscular dystrophy type 2A. Hum Mol Genet. 2000;9(9): 1393-402.

21. Kramerova I, Kudryashova E, Wu B, Germain S, Vandenborne K, Romain N, et al. Mitochondrial abnormalities, energy deficit and oxidative stress are features of calpain 3 deficiency in skeletal muscle. Hum Mol Genet. 2009; 18(17):3194-205.

22. Franko A, Mayer S, Thiel G, Mercy L, Arnould T, Hornig-Do HT, et al. CREB1alpha is recruited to and mediates upregulation of the cytochrome $C$ promoter during enhanced mitochondrial biogenesis accompanying skeletal muscle differentiation. Mol Cell Biol. 2008;28(7):2446-59.

23. Kraft CS, LeMoine CM, Lyons CN, Michaud D, Mueller CR, Moyes CD. Control of mitochondrial biogenesis during myogenesis. Am J Physiol Cell Physiol. 2006;290(4):C1119-27.

24. Moyes CD, Mathieu-Costello OA, Tsuchiya N, Filburn C, Hansford RG. Mitochondrial biogenesis during cellular differentiation. Am J Phys. 1997; 272(4 Pt 1):C1345-51.

25. Jahnke VE, Sabido O, Freyssenet D. Control of mitochondrial biogenesis, ROS level, and cytosolic $\mathrm{Ca}^{2+}$ concentration during the cell cycle and the onset of differentiation in L6E9 myoblasts. Am J Physiol Cell Physiol. 2009; 296(5):C1185-94.

26. Carafoli E. Calcium signaling: a tale for all seasons. Proc Natl Acad Sci U S A. 2002;99(3):1115-22.

27. Casas F, Pessemesse L, Grandemange S, Seyer P, Gueguen N, Baris O, et al. Overexpression of the mitochondrial T3 receptor p43 induces a shift in skeletal muscle fiber types. PLoS One. 2008;3(6):e2501.

28. Duguez S, Sabido O, Freyssenet D. Mitochondrial-dependent regulation of myoblast proliferation. Exp Cell Res. 2004;299(1):27-35.

29. Duguez S, Feasson L, Denis C, Freyssenet D. Mitochondrial biogenesis during skeletal muscle regeneration. Am J Physiol Endocrinol Metab. 2002; 282(4):E802-9. 
30. Kitsis RN, Molkentin JD. Apoptotic cell death "nixed" by an ER-mitochondrial necrotic pathway. Proc Natl Acad Sci U S A. 2008;107(20):9031-2.

31. Larsson NG. Somatic mitochondrial DNA mutations in mammalian aging. Annu Rev Biochem. 2010;79:683-706.

32. Freyssenet $D$. Energy sensing and regulation of gene expression in skeletal muscle. J Appl Physiol. 2007:102(2):529-40

33. Warburg O. On the origin of cancer cells. Science. 1956;123(3191):309-14.

34. Horn A, Van der Meulen JH, Defour A, Hogarth M, Sreetama SC, Reed A, et al. Mitochondrial redox signaling enables repair of injured skeletal muscle cells. Science signaling. 2017;10(495).

35. Sharma N, Medikayala S, Defour A, Rayavarapu S, Brown K, Hathout Y, et al. Use of quantitative membrane proteomics identifies a novel role of mitochondria in healing injured muscles. J Biol Chem. 2012;287(36):30455-67.

36. Vila MC, Rayavarapu S, Hogarth MW, Van der Meulen JH, Horn A, Defour A, et al. Mitochondria mediate cell membrane repair and contribute to Duchenne muscular dystrophy. Cell Death Differ. 2017;24(2):330-42.

37. Boehler JF, Horn A, Novak JS, Li N, Ghimbovschi S, Lundberg IE, et al. Mitochondrial dysfunction and role of harakiri in the pathogenesis of myositis. J Pathol. 2019;249(2):215-26.

38. Debattisti V, Horn A, Singh R, Seifert EL, Hogarth MW, Mazala DA, et al. Dysregulation of mitochondrial $\mathrm{Ca}^{2+}$ uptake and sarcolemma repair underlie muscle weakness and wasting in patients and mice lacking MICU1. Cell Rep. 2019:29(5):1274-86 e6.

39. Morgan JE, Beauchamp JR, Pagel CN, Peckham M, Ataliotis P, Jat PS, et al. Myogenic cell lines derived from transgenic mice carrying a thermolabile $T$ antigen: a model system for the derivation of tissue-specific and mutationspecific cell lines. Dev Biol. 1994;162(2):486-98.

40. Jahnke VE, Sabido O, Defour A, Castells J, Lefai E, Roussel D, et al. Evidence for mitochondrial respiratory deficiency in rat rhabdomyosarcoma cells. PLoS One. 2010:5(1):e8637.

41. Brooks SV, Faulkner JA. Contractile properties of skeletal muscles from young, adult and aged mice. J Physiol. 1988;404:71-82.

42. Defour A, Sreetama SC, Jaiswal JK. Imaging cell membrane injury and subcellular processes involved in repair. Journal of Visualized Experiments: JOVE. 2014(85).

43. Jahnke VE, Van Der Meulen JH, Johnston HK, Ghimbovschi S, Partridge T, Hoffman EP, et al. Metabolic remodeling agents show beneficial effects in the dystrophin-deficient mdx mouse model. Skelet Muscle. 2012;2(1):16.

44. Kilinc D, Gallo G, Barbee KA. Mechanical membrane injury induces axonal beading through localized activation of calpain. Exp Neurol. 2009;219(2): 553-61.

45. Taneike M, Mizote I, Morita T, Watanabe T, Hikoso S, Yamaguchi O, et al. Calpain protects the heart from hemodynamic stress. J Biol Chem. 2011; 286(37):32170-7.

46. Mellgren RL, Zhang W, Miyake K, McNeil PL. Calpain is required for the rapid, calcium-dependent repair of wounded plasma membrane. J Biol Chem. 2007;282(4):2567-75

47. Stuelsatz P, Pouzoulet F, Lamarre Y, Dargelos E, Poussard S, Leibovitch S, et al. Down-regulation of MyoD by calpain 3 promotes generation of reserve cells in C2C12 myoblasts. J Biol Chem. 2010;285(17):12670-83.

48. Angione AR, Jiang $C$, Pan D, Wang YX, Kuang S. PPAR regulates satellite cell proliferation and skeletal muscle regeneration. Skelet Muscle. 2011;1(1):33.

49. Wang YX, Zhang CL, Yu RT, Cho HK, Nelson MC, Bayuga-Ocampo CR, et al, Regulation of muscle fiber type and running endurance by PPARS. PLOS Biol. 2004;2(10):e294

50. Mellgren RL, Miyake K, Kramerova I, Spencer MJ, Bourg N, Bartoli M, et al. Calcium-dependent plasma membrane repair requires $\mathrm{m}$ - or mu-calpain, but not calpain-3, the proteasome, or caspases. Biochim Biophys Acta. 2009; 1793(12):1886-93.

51. Palma E, Tiepolo T, Angelin A, Sabatelli P, Maraldi NM, Basso E, et al. Genetic ablation of cyclophilin $\mathrm{D}$ rescues mitochondrial defects and prevents muscle apoptosis in collagen VI myopathic mice. Hum Mol Genet. 2009; 18(11):2024-31.

52. Irwin WA, Bergamin N, Sabatelli P, Reggiani C, Megighian A, Merlini L, et al. Mitochondrial dysfunction and apoptosis in myopathic mice with collagen VI deficiency. Nat Genet. 2003;35(4):367-71.

53. Quinlivan R, Mitsuahashi S, Sewry C, Cirak S, Aoyama C, Mooore D, et al. Muscular dystrophy with large mitochondria associated with mutations in the CHKB gene in three British patients: extending the clinical and pathological phenotype. Neuromuscul Disord. 2013;23(7):549-56.
54. Miura P, Chakkalakal JV, Boudreault L, Belanger G, Hebert RL, Renaud JM et al. Pharmacological activation of PPARbeta/delta stimulates utrophin a expression in skeletal muscle fibers and restores sarcolemmal integrity in mature mdx mice. Hum Mol Genet. 2009;18(23):4640-9.

55. Ljubicic V, Miura P, Burt M, Boudreault L, Khogali S, Lunde JA, et al. Chronic AMPK activation evokes the slow, oxidative myogenic program and triggers beneficial adaptations in mdx mouse skeletal muscle. Hum Mol Genet. 2011; 20(17):3478-93.

56. Ljubicic V, Khogali S, Renaud JM, Jasmin BJ. Chronic AMPK stimulation attenuates adaptive signaling in dystrophic skeletal muscle. Am J Physiol Cell Physiol. 2012;302(1):C110-21.

57. Ferraro E, Giammarioli AM, Chiandotto S, Spoletini I, Rosano G. Exerciseinduced skeletal muscle remodeling and metabolic adaptation: redox signaling and role of autophagy. Antioxid Redox Signal. 2014.

58. Fujioka H, Tandler B, Cohen M, Koontz D, Hoppel CL. Multiple mitochondrial alterations in a case of myopathy. Ultrastructural Pathology. 2014.

\section{Publisher's Note}

Springer Nature remains neutral with regard to jurisdictional claims in published maps and institutional affiliations.
Ready to submit your research? Choose BMC and benefit from:

- fast, convenient online submission

- thorough peer review by experienced researchers in your field

- rapid publication on acceptance

- support for research data, including large and complex data types

- gold Open Access which fosters wider collaboration and increased citations

- maximum visibility for your research: over $100 \mathrm{M}$ website views per year

At BMC, research is always in progress.

Learn more biomedcentral.com/submissions 